University of Nebraska - Lincoln

DigitalCommons@University of Nebraska - Lincoln

Sensitivity of Planetary Boundary Layer Atmosphere to Historical and Future Changes of Land Use/Land Cover, Vegetation Fraction, and Soil Moisture in Western Kentucky, USA

\author{
Rezaul Mahmood \\ University of Nebraska - Lincoln
}

Follow this and additional works at: https://digitalcommons.unl.edu/natrespapers

Part of the Natural Resources and Conservation Commons, Natural Resources Management and Policy Commons, and the Other Environmental Sciences Commons

Mahmood, Rezaul, "Sensitivity of Planetary Boundary Layer Atmosphere to Historical and Future Changes of Land Use/Land Cover, Vegetation Fraction, and Soil Moisture in Western Kentucky, USA" (2011). Papers in Natural Resources. 1256.

https://digitalcommons.unl.edu/natrespapers/1256

This Article is brought to you for free and open access by the Natural Resources, School of at DigitalCommons@University of Nebraska - Lincoln. It has been accepted for inclusion in Papers in Natural Resources by an authorized administrator of DigitalCommons@University of Nebraska - Lincoln. 


\title{
Sensitivity of planetary boundary layer atmosphere to historical and future changes of land use/land cover, vegetation fraction, and soil moisture in Western Kentucky, USA
}

\author{
Rezaul Mahmood a,b,c,*, Ronnie Leeper ${ }^{\text {b,c }}$, Arturo I. Quintanar b,c \\ a Meteorology Program, Western Kentucky University, Bowling Green, KY 42101, United States \\ b Department of Geography and Geology, Western Kentucky University, Bowling Green, KY 42101, United States \\ c Kentucky Climate Center, Western Kentucky University, Bowling Green, KY 42101, United States
}

\section{A R T I C L E I N F O}

\section{Article history:}

Received 18 September 2009

Accepted 16 May 2011

Available online 23 May 2011

\section{Keywords:}

land use induced land cover change

vegetation fraction

MM5

planetary boundary layer

surface energy balance

\begin{abstract}
A B S T R A C T
Changes in land use land cover (LULCC), vegetation fraction (FV), and soil moisture affects land surface atmosphere interactions, characteristics of planetary boundary layer (PBL), and near surface atmospheric moisture content. Previous studies have investigated impacts of LULC, FV, and soil moisture changes on atmosphere separately. The present study investigates the combined impacts of changes in LULC, FV, and soil moisture, on PBL atmosphere and near surface atmospheric moisture content. The study is set in western region of Kentucky, USA. We have used the Noah land surface scheme and MM5 model for this purpose. The study used two nested domains. The current land use land cover of the inner domain was changed to grass, forest, and bare soil to represent historical changes and potential near future modifications. Subsequently, FV and soil moisture were systematically changed for each of the land uses. The simulations have found that changes of current land use to grass within the inner domain increases latent heat flux, dew point temperature, relative humidity, and equivalent potential temperature. It was found that height of the PBL was reduced and development of circulation cells was visible along land use land cover discontinuity. Changes in horizontal and vertical wind field were also reported. FV changes for grass further magnified these impacts. For example, decrease or increase in FV has decreased or increased latent heat flux. Similar response of other PBL parameters could be found for changes in FV along with LULC. It was also found that if we replaced forest with lower FV by grass with higher FV, the impacts could cancel each other. Changes to forest and bare soil land use types and lower FV for forest also produced generally similar types of responses. Soil moisture changes, particularly drying, further impacted these responses. This study finds that increase in FV counteracts impacts of soil moisture reduction up to a level. Overall, grass produced moister PBL and lowered the height of PBL and LCL. It is interesting to note that during nighttime the impacts of LULC, FV and soil moisture changes were diminished. These changes not only modified meso-scale wind fields but also potential for convective development. It was concluded that similar experiments needed to be undertaken for convectively conducive environments to better understand the combined impacts of changes in LULC, FV and soil moisture.
\end{abstract}

(c) 2011 Elsevier B.V. All rights reserved.

\section{Introduction}

Land use induced land cover change (LULCC) can produce profound impact on regional land-surface atmosphere interactions and planetary boundary layer (Pielke, 2001; Cui et al., 2006; Mahmood et al., 2006; Ter Maat et al., 2006; Pielke et al., 2007a, b; Raddatz, 2007). Recently, a report by the National Research Council (NRC) emphasized that LULCC should be included in the climate change assessment and should be considered as an important climate

\footnotetext{
* Corresponding author at: Meteorology Program, Western Kentucky University Bowling Green, KY 42101, United States. Tel.: + 1270745 5979; fax: + 12707456410. E-mail address: rezaul.mahmood@wku.edu (R. Mahmood).
}

forcing (NRC, 2005). Recently, several other assessments also highlighted the importance of LULCC in the climate system (Mahmood et al., 2010; McAlpine et al., 2010). Land use/land cover (LULC) of the western Kentucky has been modified significantly during pre-European settlement (Sauer, 1927; Waisanen and Bliss, 2002; and Dobler, 2007). This region includes the Green River watershed and it will continue to be reshaped in the near future with farming subsidy programs such as the Conservation Reserve Enhancement Program (CREP). In addition, land surface in western Kentucky is dominated by karst geology which allows rapid runoff of precipitation in the underground streams.

Historical data of anthropogenic land management strategies by the Native Americans across the Southeast date back to the 16th century (Hammett, 1992). These land management strategies consisted of 
yearly burnings and clearing of forests and in some instances grassland to increase visibility for hunts and war, to establish villages and agriculture, and to enhance the availability of certain resources (Michaux, 1805; Gordon, 1953; Hammett, 1992). The consistent clearing of land in March or April was followed by re-growth of new vegetation several weeks later (Michaux, 1805), which attributed to a landscape in a constant state of flux even prior to European settlement. Changes in LULC continue today across the commonwealth with the US Department of Agriculture and the Commonwealth of Kentucky partnering together to implement the Conservation Reserve Enhancement Program (CREP) (Kentucky Division of Conservation, 2008). CREP is designed to subsidize land owners over regions of Kentucky, including areas of western Kentucky, to plant grasses and trees native to this region. As the largest conservation effort in Kentucky's history, initiated in 2001, the program has been active for nearly nine years and has allowed for some re-growth of native vegetation. Hence, it is necessary to understand the impacts of the various land uses and changes in western Kentucky on planetary boundary layer (PBL). Note, in this study PBL, lower atmosphere, and near surface atmosphere have been used interchangeably.

The importance of LULCC and atmospheric interactions and associated feedbacks has been well documented (Pielke et al., 1999; Fu, 2003; Narisma and Pitman, 2003; Schneider and Eugster, 2005; Adegoke et al., 2007; and Pielke et al., 2007a). LULCC transforms landatmosphere interactions by altering the distribution of moisture and energy (Pielke, 2001; Gero and Pitman, 2006). LULCC influences the hydrological cycle and the partitioning of available energy, resulting in atmospheric and soil moisture feed-backs through changes in vegetative bio-physical properties and vegetation fraction (Chang and Wetzel, 1991; Barlage and Zeng, 2004). Numerous studies have used models to simulate the impacts of LULCC on convective precipitation, wind fields, temperature, soil moisture, water vapor, and cloud development (Chang and Wetzel, 1991; Clark and Arritt, 1995; Shen, 1998; Crawford et al., 2001; Pielke, 2001; Adegoke et al., 2003; Narisma and Pitman, 2003; Gero and Pitman, 2006; Sen Roy et al., 2007, 2011). Shen (1998) found a vegetation-forced enhancement of simulated lake breezes for vegetated surfaces over bare soil due to increases in available energy. Adegoke et al. (2007) have also shown this type of increase in available energy at the surface due to lower albedo. The increase in available energy from vegetated surfaces has been shown to have profound effects on the development of convectively driven thunderstorms and rain (Pielke, 2001; Pielke et al., 2007a).

Variations in vegetation fraction (FV) have also been shown to influence the partitioning of available energy and moisture (Chang and Wetzel, 1991; Clark and Arritt, 1995; Fu, 2003; and Barlage and Zeng, 2004). Increased (decreased) vegetation fraction reduces (increases) the amount of solar radiation absorbed by the soil, increases (reduces) transpiration from vegetative surfaces, and thus impacts both energy and subsurface moisture available to the atmosphere. Chang and Wetzel (1991) demonstrated that changes in FV resulted in differential heating of land surface and enhancement of a stationary boundary front. It was also noted that higher vegetation fraction caused early initiation of precipitation with higher rainfall intensities (Clark and Arritt, 1995). Zeng et al. (2003) found that fractional vegetation cover is one of the more important variables to be considered in land surface modeling.

It is well known that soil moisture is a critical component of the climate system and it plays an important role in distribution of moisture and energy through soil moisture-atmosphere feedbacks (McCumber and Pielke, 1981; Chen and Avissar, 1994; Mahmood, 1996; Mahmood and Hubbard, 2002, 2004, 2007; LeMone et al., 2007). Moreover, soil moisture modifies day time PBL evolution (Zhang and Anthes, 1982), surface Bowen ratio, convective available potential energy (CAPE) (Clark and Arritt, 1995; Pielke, 2001), cloud development (Findell and Eltahir, 2003; Ek and Holtslag, 2004), PBL wind field (Segal and Arritt, 1992) and precipitation (Ookouchi et al., 1984; Pan et al., 1996). Brubaker et al. (1993) noted that 10 to $40 \%$ of atmospheric water vapor is derived "directly" through local evapotranspiration over the Mississippi Valley. It is evident that this local supply of atmospheric moisture is particularly necessary for the development of clouds and subsequent precipitation when the atmosphere is dry (Chen and Avissar, 1994).

In addition, under synoptically weak atmospheric conditions, soil moisture-atmosphere feedbacks have been found to generate convection and precipitation (Ookouchi et al., 1984; Segal et al., 1988; Chen and Avissar, 1994; Clark and Arritt, 1995; Pielke, 2001). Chen and Avissar (1994) and Pielke (2001) both noted the importance of water vapor availability in simulated convection and precipitation processes. In a modeling study, thirty day integration for the month of July 1993 over the United States revealed a sensitivity of simulated precipitation to changes in soil moisture (Betts et al., 1996). Similarly, Douville et al. (2001) noted an increase in modeled precipitation over the African continent as a result of increased soil moisture during the wet monsoon season. Findell and Eltahir (2003) have found wetter soils both increase and decrease simulated convection and accumulated precipitation depending on the initial state of the upper level atmosphere.

Mahmood and Hubbard (2002 and 2007) noted that different vegetation types uptake dissimilar quantities of soil moisture depending upon phenological stage, stomatal resistance, and vegetation density. Accurate representations of both subsurface moisture and overlying vegetation increase atmospheric models' ability to resolve thermal gradients caused by differential heating at the surface (Grasso, 2000). Similarly, Chang and Wetzel (1991) found model simulations initialized with proper representations of both soil moisture and FV resulted in improved forecasts over experiments that included only changes in soil moisture or FV alone. Assessing the relationship between soil moisture and evaporative fraction, Dirmeyer et al. (2000) concluded that evaporative fraction was sensitive to both soil moisture and overlying vegetation. Hence, the role of overlying vegetation cover must be considered in soil moistureatmosphere feedback studies.

In this context, the present study assesses sensitivity of warm season near-surface atmosphere to historical, recent, and potential future changes in LULC, FV, and soil moisture over western Kentucky. To represent these changes, the land uses considered are grass, forest, and bare soils. Grass represents seasonal modifications made by the Native Americans and early European settlers (ca. 1700s), forest represents historic and recent predominant LULC (ca. 1700-1900) and bare soil represents future extreme changes (ca 2000s). Grass and forest LULC was considered with 25, 50, 75, and 100\% FV (no FV for bare soils). Systematic changes in initial soil moisture (throughout the depth of the column) include domain wide increases and decreases by $0.05,0.10$, and $0.15 \mathrm{~m}^{3} \mathrm{~m}^{-3}$. These lower soil moisture scenarios are referred to as DRY05, DRY10, and DRY15. On the other hand, increases in soil moisture are referred to as WET05, WET10, and WET15. Moreover, in the subsequent sections of this paper control simulation is referred to as CTRL. The model was run for 11 days of June, 2005. We agree with Beltran-Przekurat et al. (2008) that observational studies sometime only provide a contemporary view while modeling studies permit to investigate historical changes and their impacts. Additional details on experiment set-up are provided in Section 2. Moreover, an expanded version of the part of the results could be found in Leeper et al. (2009).

LULCC could accompany changes in FV. In addition, there are uncertainties associated with the currently prescribed land use and FV provided in the USGS land cover datasets. By systematically changing the FV, we also address these uncertainties and the impacts of LULCC. This approach, in turn, makes the study more robust. In the past, similar research design was adopted by Hoffmann and Jackson (2000) to overcome uncertainty in the LULC data set. Additionally, currently, adjoining regions of the study area are also experiencing various development activities and expansion of human settlement. This also provided motivation for the current assessment and influenced the experimental design. This investigation is part of a larger research 
initiative (e. g., Quintanar et al., 2008, 2009). The study is set under rather stable atmospheric condition dominated by a high pressure system. We are in the process of taking similar studies for convective and unstable conditions.

Literature review suggests that there is a lack of research that has focused on combined effect of changes in historical land use land cover, vegetation fraction (FV), and soil moisture on various components of hydrologic cycle in the lower atmosphere and planetary boundary layer. Other studies have provided -1 or 2-D assessment. To our knowledge this study provided first 3-D impacts assessment of LULCC. For example, Clark and Arritt (1995) applied changes in FV without changing the land use. Our study included changes in land use land cover, FV, and soil moisture. Hence, this assessment is complimentary to the Clark and Arritt (1995) and other similar research. It is possible to intuitively conclude the potential impacts of changes in soil moisture and FV alone. However, we will demonstrate that the combined changes in land use land cover, FV, soil moisture and their impacts are more complex. In addition, the current investigation provides a quantitative measure of combined impacts of these changes, in addition to conceptual understanding.

In order to simulate the impacts of LULCC, the Pennsylvania State University, National Center for Atmospheric Research's (NCAR) fifth generation mesoscale model (MM5) was applied. The MM5 has been widely used in LULCC studies in the past (e. g, Fu, 2003; Narisma and Pitman, 2003; Grossman-Clarke et al., 2005; and McPherson and Stensurd, 2005). A large number of model-based studies were completed to understand the impacts of LULCC in the Great Plains. This study was set in western Kentucky, a region east of the Great Plains and west of the Appalachian Mountains characterized by small changes in elevation and land cover types consisting of forests and grasslands. Hence, it provides a new ecological setting for land surface atmosphere interactions studies. Moreover, as indicated above, it is expected that simulated combined modifications of LULC, FV, and soil moisture will provide better understanding of these changes on planetary boundary layer development and near-surface atmospheric hydrological components.

\section{Model description and verification}

\subsection{The MM5 model}

The MM5 was used in this study to simulate systematic changes of land use land cover, vegetation fraction, and soil moisture. The MM5 version 3 is a non-hydrostatic, atmospheric research model that is capable of resolving localized topographical, urban, and coastal impacts on synoptic scale systems through nested grids (Dudhia, 1993). This model uses a set of four-dimensional equations for a fully compressible atmosphere in a rotating frame of reference at user defined resolutions (Dudhia, 1993; NCAR, 2006). The MM5 also incorporates terrain following coordinates, real-time data assimilation, three-dimensional coriolis torque, and a suite of physics options including: cumulus parameterization, planetary boundary layer, explicit moisture, and surface radiation schemes.

In addition MM5 was coupled with the Noah land surface model (LSM) (Chen and Dudhia, 2001; Mitchell, 2001). The Noah LSM incorporates bio-physical vegetation parameters, including, roughness length, stomatal resistance, root depth, leaf area index, and soil characteristics to simulate surface energy and moisture budgets. The hydrological model of Noah is a column model that allows moisture to percolate downward from the force of gravity in addition upward movement of capillary action through vegetation roots. Precipitation that reaches the Earth's surface either infiltrates, moves along the ground as runoff, evaporates, or for evapotranspires. After infiltration, moisture moves through the four soil layers (at depths of 10, 30, 60, and $100 \mathrm{~cm}$ ) where it is either move upward through capillary action for ET or further downward. In addition, moisture availability from the four soil layers for evapotranspiration is limited by rooting depth, which is a function of vegetation type. Evaporation from Noah is broken into three parts: direct evaporation from the soil, evaporation from the canopy (water on leaves), and transpiration through the vegetation stomata. Transpiration is a function of vegetation fraction, potential evaporation, surface exchange coefficients for heat and moisture, and canopy resistance. In addition, canopy resistance is further dependent upon solar radiation, vapor pressure deficit, air temperature, soil moisture availability and LAI. For further information please consult Chen and Dudhia (2001).

The hydrological model is further impacted by FV, as it partitions total evaporation between direct evaporation from the soil, canopy transpiration, and canopy evaporation (Chen and Dudhia, 2001). Modeled canopy transpiration is extracted from simulated soil moisture content. The LSM integrates soil moisture over the four depths up to $1 \mathrm{~m}$. Other components include soil water diffusivity, hydraulic conductivity, and surface runoff. The Noah LSM has been tested against several other widely used LSMs, and reasonably reproduced observed energy fluxes, temperature, and atmospheric and subsurface moisture (Chen and Dudhia, 2001). Based on these results, the well-accepted fundamental theories of hydrology that provided the basis for many assumptions in the model, wide applications in many parts of the world, and the large community (scientific and operational) of users, we believe that the Noah LSM is the right model for our study region.

For this study, the MM5 was initialized with simple ice microphysics, Kain-Fritsch cumulus parameterization, the Eta planetary boundary layer scheme, and two nested domains at nine and three kilometer resolution for the outer and inner domains, respectively. Previously, these authors (Quintanar et al., 2008) have conducted a series of experiments for domain sizes and their impacts on accuracy of simulating a number of precipitation events under a variety of synoptic forcings for the study region presented here. Based on the results of these experiments and relatively stable synoptic conditions (with no precipitation) during the current study period, it is determined that adopted domain size would provide satisfactory results. Verification of control model runs (Section 2.2) also provided evidence that adopted domain sizes produced realistic simulations of land surface conditions. The outer and inner domains are centered at $37.5^{\circ} \mathrm{N}$ and $87.0^{\circ} \mathrm{W}$ with $35 \times 41$ and $49 \times 64$ grid-point resolution, respectively (Fig. 1). Twenty-three vertical levels were used in this study to increase computer efficiency and resources. Initial boundary conditions were forced using final analysis data (FNL) provided by the NCEP at $1 \times 1$ resolution integrated over a time-step of $30 \mathrm{~s}$. The selection of physics options, time-step, and resolution of model domains were made based upon a series of sensitivity tests that fit best against observations for the CTRL run (not shown here).

The current land cover consists of a mixture of forest, grassland, and cropland as represented by the USGS 24-Category land use data set. As noted above, in order to capture the significance of impacts of LULCC on planetary boundary layer components, a series of sensitivity experiments were conducted. Simulated changes include conversion of current (CTRL) vegetation to grass, forests, and bare soil land cover. Subsequently, FV was modified (from current $85 \%$ ) to $25,50,75$, and $100 \%$ for grass and forest to determine combined impacts of LULC and FV change. These FV percentages are in reference to individual grid cells and, for example, model assumes $25 \% \mathrm{FV}$ is evenly distributed throughout the grid cell. However, no FV experiments were considered for bare soil.

Soil moisture was systematically changed for grass and forest and each FV associated with these LULCC throughout the soil column (all four levels). Soil moisture was also modified for bare soil. As noted previously, soil moisture was increased and decreased by $0.05,0.10$, and $0.15 \mathrm{~m}^{3} \mathrm{~m}^{-3}$ from the CTRL for this study. In addition, these changes were applied uniformly across the entire inner domain. 


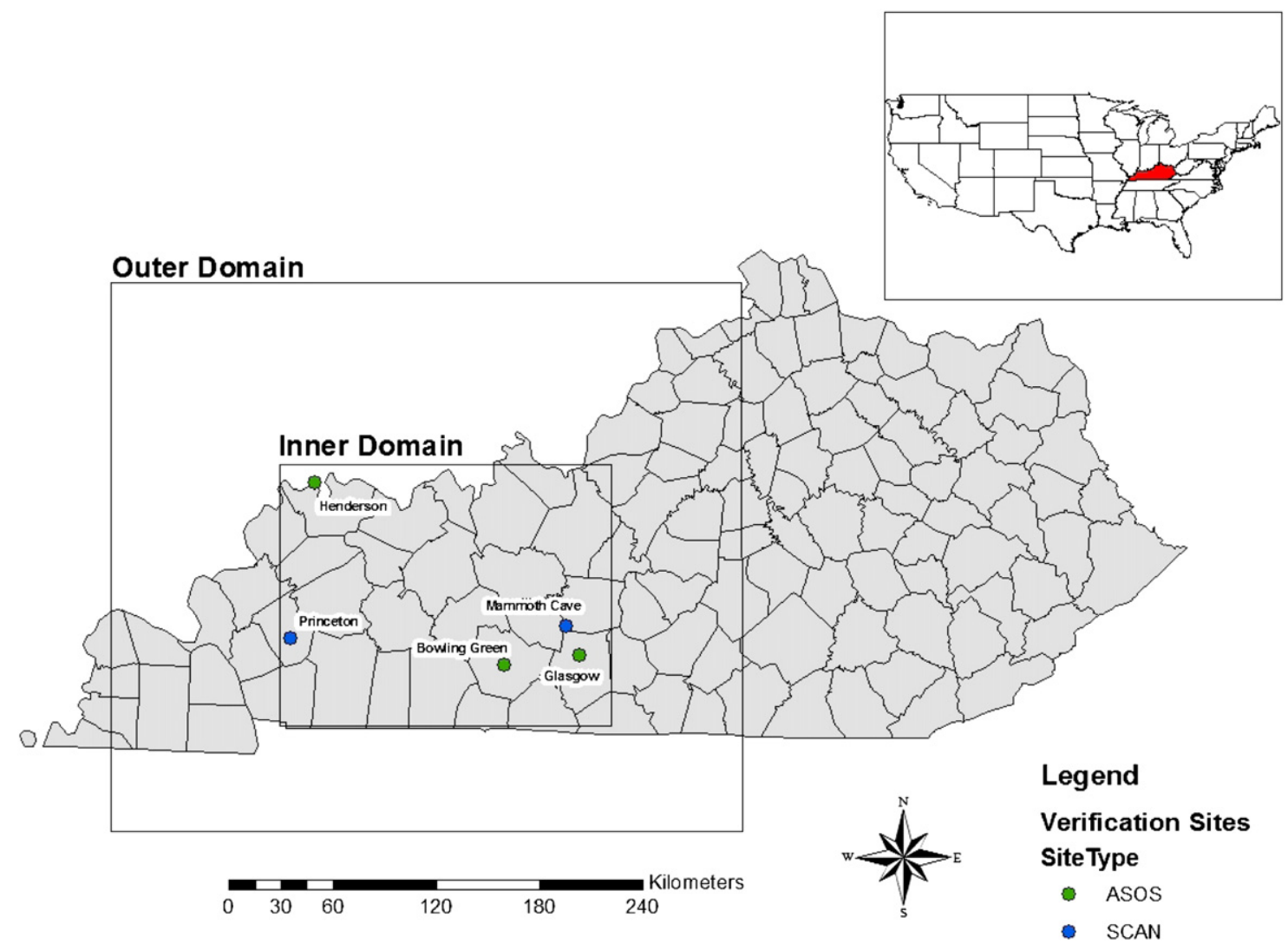

Fig. 1. Outer and inner model domains with locations of Automated Surface Observing System (ASOS) and Soil Climate Analysis Network (SCAN) verification sites.

Over the study region (Kentucky), there are two sites that measured soil moisture. The data is collected by Soil Climate Analysis Network (SCAN) and maintained by the Natural Resource Conservation Service (NRCS) of the United States Department of Agriculture. These two sites collect hourly soil moisture data from five depths up to $1 \mathrm{~m}$. The data could be freely accessed through the World Wide Web (http://www.wcc.nrcs.usda.gov/scan/). Inspection of these data suggests that the soil moisture modification scenarios were realistic and fits to observations. In addition, Leeper et al. (accepted for publication); Miguez-Macho et al. (2008), Trenbreth and Guillemot (1998) and Higgins et al. (1996) have noted tendency for reanalysis datasets (such as NARR) have a tendency to contain moist bias in soil moisture, which likely stems from a common practice of not balancing moisture budgets and lack of assimilating soil moisture data into their products (Nigam and Ruiz-Barradas, 2006). In order to account for this bias and include potential water shortages or moist conditions in the past or in the future, we allowed soil moisture to vary the way as noted above.

All modeled results were compared to the CTRL run and presented as LULCC minus CTRL simulations. Modeling scenarios were initialized with the same set of initial and lateral boundary conditions. The initial four days allowed the model to adjust to simulated changes in LULC and the final seven days were used in the analysis. During this period, a synoptic condition dominated by large-scale high pressure system that existed across much of the Ohio valley (including the study region) with typical dry summer time temperatures near lower $30 \mathrm{~s}\left({ }^{\circ} \mathrm{C}\right)$ for highs and mid to upper teens $\left({ }^{\circ} \mathrm{C}\right)$ for lows. Less than trace amount of precipitation was recorded in the study region.

\subsection{Model verification}

Simulation of current (CTRL) conditions were verified with hourly observations taken from both Automated Surface Observing System
(ASOS) and Soil Climate Analysis Network (SCAN) sites operated by the National Climatic Data Center (NCDC) and the Natural Resources Conservation Service (NRCS), respectively (e. g., Adegoke et al., 2003). The SCAN network additionally provided soil moisture and temperature observations at five depths: 5, 10, 20, 50, and $100 \mathrm{~cm}$. Three ASOS and two SCAN sites were located within modeled domains that had observations at appropriate time intervals for the 15th through the 26th of June, 2005. Comparisons of modeled and observed data were conducted by using a series of statistical tests including the coefficient of determination $\left(r^{2}\right)$, root mean square error (RMSE), $d$-index, and the mean absolute error (MAE). All weather stations included in this analysis were not equipped to observe the same set of meteorological observations. For example, SCAN sites were equipped to observe relative humidity while ASOS stations provided dew point temperature. Also, modeled soil moisture results were only comparable with observations at two depths $(0.1$ and $1 \mathrm{~m}$ ) due to the model's additional specified depths and depths for observations did not match. The three ASOS stations included were Henderson, Glasgow, and Bowling Green and two SCAN sites were Mammoth Cave and Princeton (Fig. 1).

The statistical results reveal that the model simulations were generally in agreement with observed atmospheric conditions. Modeled relative humidity show $r^{2}$ of 0.58 and 0.56 for Mammoth Cave and Princeton, respectively (Table 1). MAE and RMSE ranged between 9$12 \%$ and $11-14 \%$, respectively, for these locations. It is argued that the $d$-index provides a better evaluation of model performance since some of the above measures are sensitive to outliers (Legates and McCabe, 1999). The $d$-index for relative humidity at Mammoth Cave and Princeton is 0.82 and 0.85 , respectively.

The $r^{2}$ values for modeled and observed dew point temperature at ASOS stations varied between 0.60 and 0.69 (Table 1). MAE and RMSE for dew point temperature for ASOS sites were in between $1.3-3.5^{\circ} \mathrm{C}$ and $1.69-3.78{ }^{\circ} \mathrm{C}$, respectively. On the other hand, $d$-index ranged between 0.62 and 0.86 . Upon further examination of simulated 
Table 1

Model verification statistics for relative humidity (\%) and dew point temperature $\left({ }^{\circ} \mathrm{C}\right)$.

\begin{tabular}{lccccc}
\hline Statistic & Mammoth Cave & Princeton & Bowling Green & Glasgow & Henderson \\
\hline$r^{2}$ & 0.58 & 0.56 & 0.60 & 0.69 & 0.63 \\
d-index & 0.82 & 0.85 & 0.86 & 0.62 & 0.73 \\
RMSE & $14(\%)$ & $11(\%)$ & $1.69\left({ }^{\circ} \mathrm{C}\right)$ & $3.78\left({ }^{\circ} \mathrm{C}\right)$ & $3.03\left({ }^{\circ} \mathrm{C}\right)$ \\
MAE & $12(\%)$ & $9(\%)$ & $1.31\left({ }^{\circ} \mathrm{C}\right)$ & $3.5\left({ }^{\circ} \mathrm{C}\right)$ & $2.61\left({ }^{\circ} \mathrm{C}\right)$ \\
\hline
\end{tabular}

atmospheric moisture, it appeared that the model tended to over and under estimate lower and higher observed values, respectively, for atmospheric moisture measures (Fig. 2a-b). Time series of modeled and observed relative humidity and dew point temperature suggests that the model satisfactorily captured the trend in atmospheric moisture (Fig. 2c-d). Relative humidity and dew point temperatures were modeled well during the early period of the simulation (June 15 through June 21).

The model was a better predictor of $2 \mathrm{~m}$ temperature (Table 2 ). The $r^{2}$ and $d$-index for $2 \mathrm{~m}$ temperature for all sites ranged between 0.71-0.86 and 0.91-0.95, respectively. On the other hand, MAE and RMSE at all sites ranged between $1.54-2.02{ }^{\circ} \mathrm{C}$ and $1.99-2.87^{\circ} \mathrm{C}$, respectively. An example of the model's performance in regard to simulated two meter temperature is shown in Fig. 3a-b. The model has a tendency to overestimate lower temperatures and is in agreement with Colle et al. (2003).

a

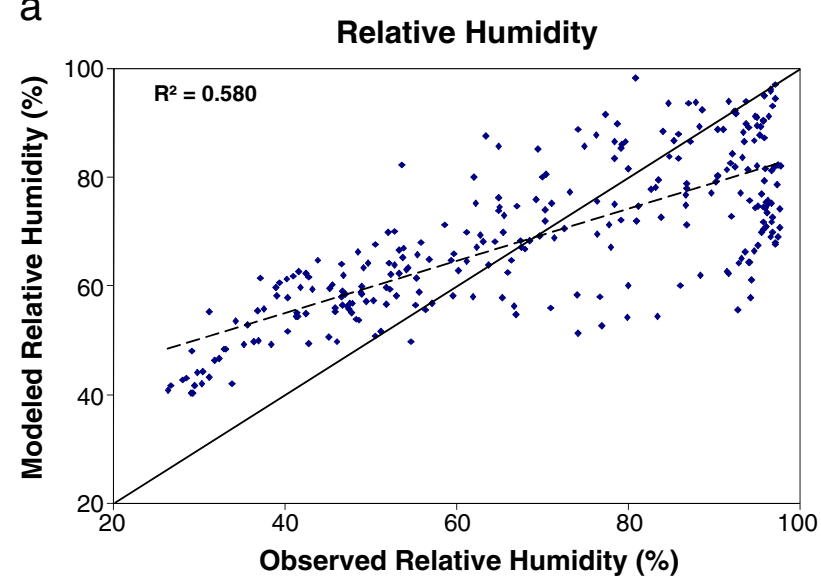

C

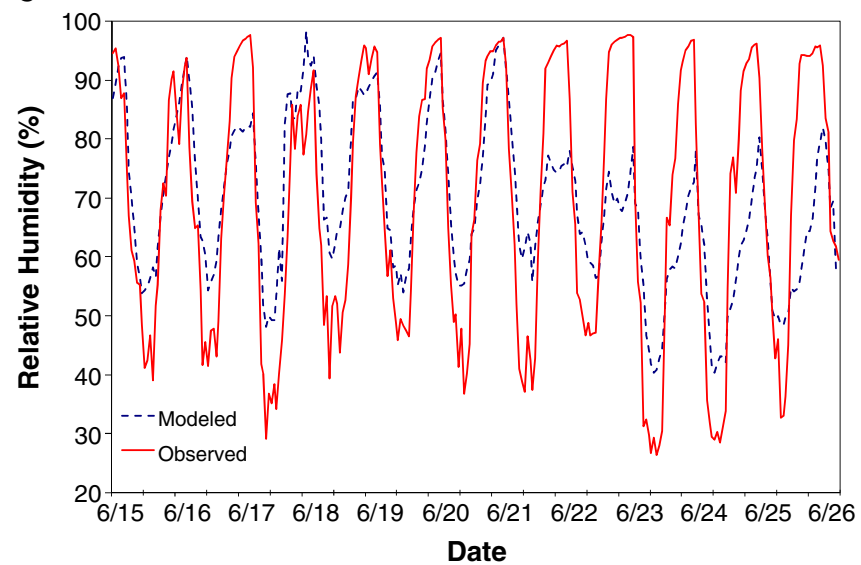

Table 2

Model verification statistics for $2 \mathrm{~m}$ temperature $\left({ }^{\circ} \mathrm{C}\right)$.

\begin{tabular}{llllll}
\hline Statistic & Bowling Green & Glasgow & Henderson & Mammoth Cave & Princeton \\
\hline$r^{2}$ & 0.71 & 0.80 & 0.82 & 0.86 & 0.84 \\
$d$-index & 0.91 & 0.94 & 0.94 & 0.94 & 0.95 \\
RMSE $\left({ }^{\circ} \mathrm{C}\right)$ & 2.87 & 2.24 & 2.39 & 2.49 & 1.99 \\
$\operatorname{MAE}\left({ }^{\circ} \mathrm{C}\right)$ & 1.99 & 1.69 & 1.89 & 2.02 & 1.54 \\
\hline
\end{tabular}

Modeled soil moisture were compared to observations at 0.1 and $1 \mathrm{~m}$ depths, as these were the only two coinciding depths of both observed and modeled soil moisture. The $r^{2}$ ranged between 0.67 and 0.97 for both depths (Table 3 ). At a depth of $0.1 \mathrm{~m}$, the model has a moist bias and tended to overestimate low soil moisture. Differences could be partially attributed to bias in the soil moisture data available for model initialization.

\section{Results and discussions}

\subsection{Control simulation}

The current land cover consists mainly of grasses (13\%) and forests (74\%) with the remaining inner domain's vegetation composed of croplands and shrubs. The vegetation fraction during the summer
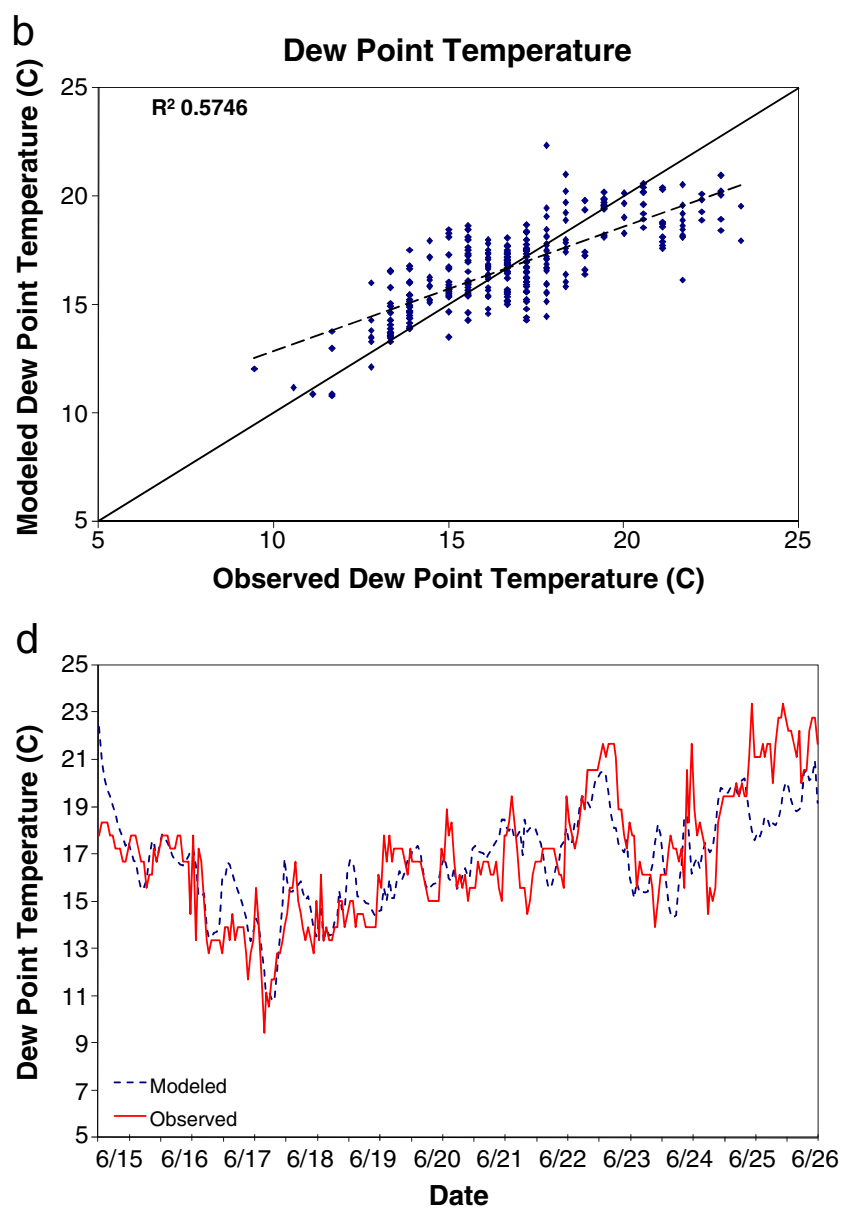

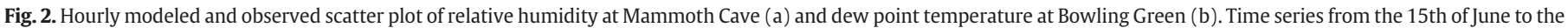

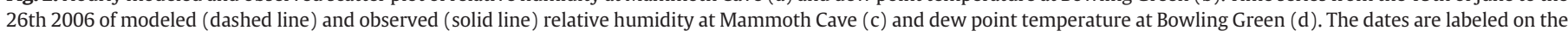
time series graphs at noon for each day. 

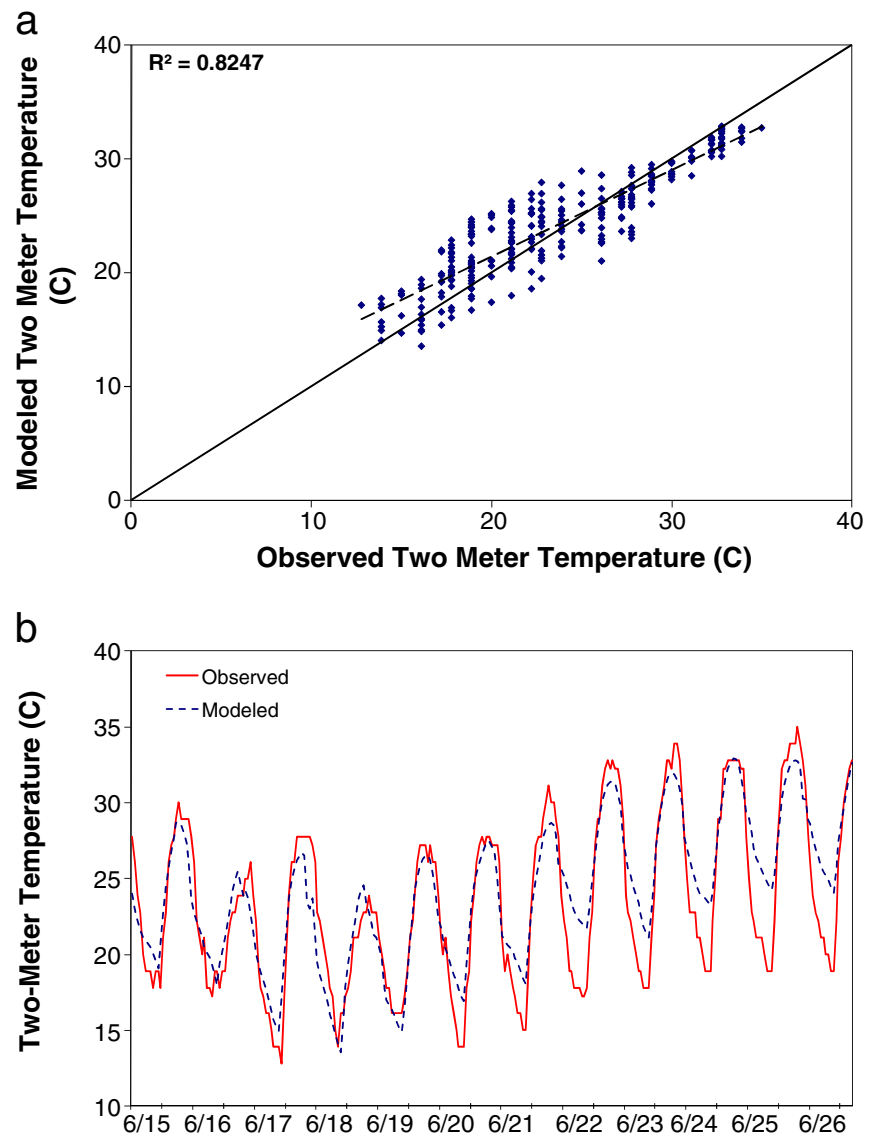

Fig. 3. Hourly modeled and observed scatter plots and time series of two-meter temperature at Henderson.

months for this area is nearly $85 \%$ and silt-loam is the dominant soil texture. Domain averages of latent and sensible heat fluxes were 198 and $42 \mathrm{~W} \mathrm{~m}^{-2}$ (Table 4). Moreover, relative humidity, ground surface, $2 \mathrm{~m}$, and dew point temperatures were $64 \%, 25.9,25.0$, and $17.7^{\circ} \mathrm{C}$, respectively (Table 4). Also, domain average PBL height was $401 \mathrm{~m}$ (Table 4). These results are similar to summer time climatological averages of this region which is $23{ }^{\circ} \mathrm{C}$ (Kentucky Climate Center, 2008). Furthermore, recall that modeled results for five sites located within the inner domain matched observations at each of the locations well. Figs. 4a-b and 5a-e show diurnal variation of these parameters for CTRL, grass, forest, and bare soil experiments. Additional discussion is presented in the following sections.

3.2. Impacts of land use land cover, fractional vegetation, and soil moisture change

\subsubsection{Grass}

Under the grass land use simulation, domain average latent heat and sensible heat flux, relative humidity, and ground surface, two

Table 3

Model verification statistics for 0.1 and $1 \mathrm{~m}$ depth soil moisture. Observed data were obtained from the SCAN sites.

\begin{tabular}{lllll}
\hline Statistic & $\begin{array}{l}\text { Mammoth Cave } \\
0.1 \mathrm{~m}\end{array}$ & $\begin{array}{l}\text { Princeton } \\
0.1 \mathrm{~m}\end{array}$ & $\begin{array}{l}\text { Mammoth Cave } \\
1 \mathrm{~m}\end{array}$ & $\begin{array}{l}\text { Princeton } \\
1 \mathrm{~m}\end{array}$ \\
\hline$r^{2}$ & 0.97 & 0.93 & 0.67 & 0.95 \\
$d$-index & 0.29 & 0.68 & 0.00 & 0.20 \\
$\begin{array}{l}\text { RMSE } \\
\left(\mathrm{m}^{3} \mathrm{~m}^{-3}\right)\end{array}$ & 21.61 & 3.07 & 6.92 & 4.81 \\
$\begin{array}{c}\mathrm{MAE} \\
\left(\mathrm{m}^{3} \mathrm{~m}^{-3}\right)\end{array}$ & 21.32 & 2.39 & 6.78 & 4.74 \\
\hline
\end{tabular}

Table 4

Modeled inner domain area average estimates of selected variables for DRY grassland experiments.

\begin{tabular}{lllllllll}
\hline $\begin{array}{l}\text { Land-use } \\
\text { and FV }\end{array}$ & SM & $\begin{array}{l}\text { Latent } \\
\text { heat } \\
\left(\mathrm{Wm}^{-2}\right)\end{array}$ & $\begin{array}{l}\text { Sensible } \\
\text { heat } \\
\left(\mathrm{Wm}^{-2}\right)\end{array}$ & $\begin{array}{l}\text { Rel. } \\
\text { humid. } \\
(\%)\end{array}$ & $\begin{array}{l}\text { Dew } \\
\text { point } \\
\left({ }^{\circ} \mathrm{C}\right)\end{array}$ & $\begin{array}{l}\text { Ground } \\
\text { temp. } \\
\left({ }^{\circ} \mathrm{C}\right)\end{array}$ & $\begin{array}{l}2 \mathrm{~m} \\
\text { Temp. } \\
\left({ }^{\circ} \mathrm{C}\right)\end{array}$ & $\begin{array}{l}\text { PBL } \\
\text { height } \\
(\mathrm{m})\end{array}$ \\
\hline CTRL & CTRL & 198 & 42 & 64 & 17.7 & 25.0 & 25.9 & 401 \\
Grass & CTRL & 202 & 33 & 68 & 18.3 & 24.8 & 25.4 & 340 \\
FV 25\% & CTRL & 140 & 70 & 57 & 16.7 & 28.3 & 26.6 & 535 \\
& DRY05 & 120 & 85 & 54 & 16.2 & 29.1 & 27.1 & 589 \\
& DRY10 & 91 & 101 & 52 & 15.8 & 29.9 & 27.6 & 640 \\
& DRY15 & 76 & 115 & 50 & 15.4 & 30.6 & 28.0 & 691 \\
FV 50\% & CTRL & 166 & 54 & 59 & 17.0 & 27.2 & 26.0 & 479 \\
& DRY05 & 153 & 65 & 56 & 16.5 & 27.9 & 26.4 & 528 \\
& DRY10 & 136 & 77 & 54 & 16.1 & 28.5 & 26.8 & 574 \\
& DRY15 & 117 & 91 & 52 & 15.7 & 29.3 & 27.2 & 635 \\
FV 75\% & CTRL & 189 & 40 & 63 & 17.6 & 26.1 & 25.3 & 394 \\
& DRY05 & 181 & 46 & 60 & 17.1 & 26.5 & 25.6 & 431 \\
& DRY10 & 170 & 55 & 58 & 16.7 & 27.2 & 26.0 & 483 \\
& DRY15 & 151 & 68 & 55 & 16.1 & 27.9 & 26.4 & 546 \\
FV 100\% & CTRL & 210 & 28 & 70 & 18.6 & 25.0 & 24.5 & 302 \\
& DRY05 & 206 & 31 & 68 & 18.4 & 25.3 & 24.7 & 320 \\
& DRY10 & 198 & 37 & 65 & 17.8 & 25.8 & 25.1 & 357 \\
& DRY15 & 180 & 50 & 59 & 16.9 & 26.7 & 25.6 & 432 \\
\hline
\end{tabular}

meter, and dew point temperatures, and PBL were, 202 and $33 \mathrm{~W} \mathrm{~m}^{-2}, 68 \%, 25.4,24.8$ and $18.3^{\circ} \mathrm{C}$, and $340 \mathrm{~m}$, respectively (Table 4). Compared to CTRL (grass minus CTRL), latent heat flux, relative humidity, and dew point temperature were increased up to $4 \mathrm{~W} \mathrm{~m}^{-2}, 4 \%$, and $0.6{ }^{\circ} \mathrm{C}$, respectively. On the other hand, domain average sensible heat flux, ground surface and $2 \mathrm{~m}$ temperatures, and height of the PBL was decreased by $9 \mathrm{~W} \mathrm{~m}^{-2}, 0.2^{\circ} \mathrm{C}$, and $0.5^{\circ} \mathrm{C}$, and $61 \mathrm{~m}$, respectively (Table 4 ).
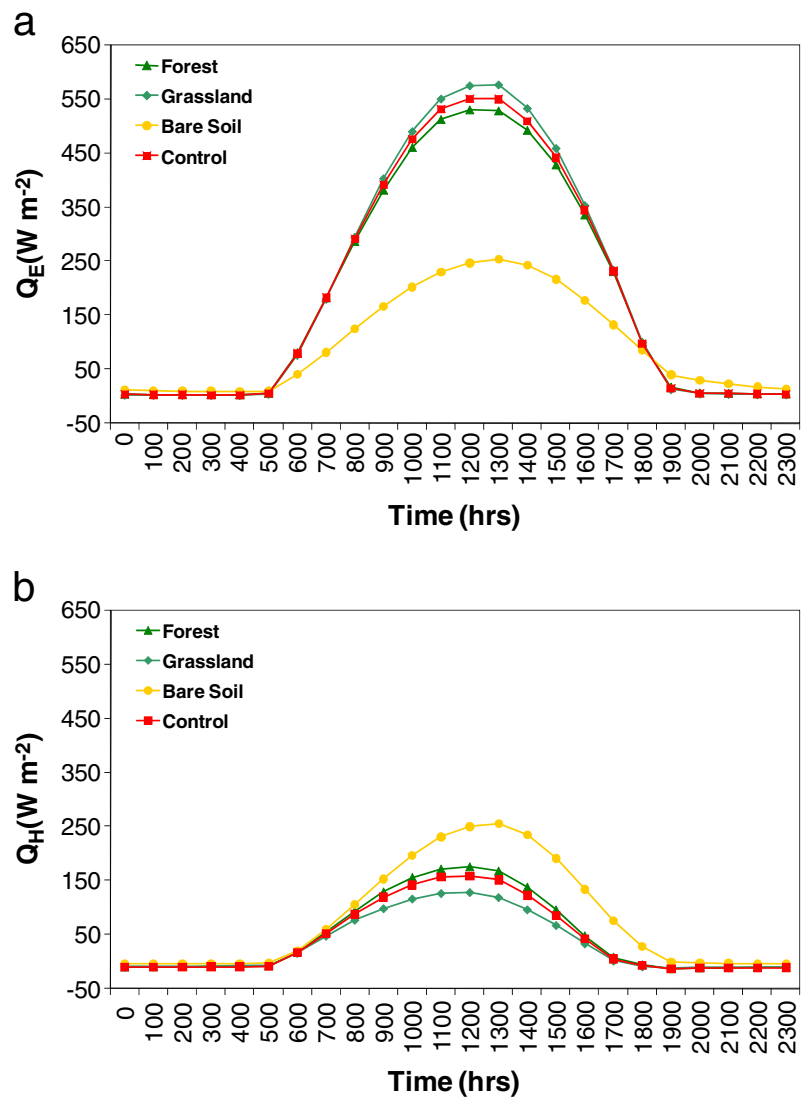

Fig. 4. Inner domain average modeled latent and sensible heat flux for control, bare soil, grassland, and forest simulations. 
a

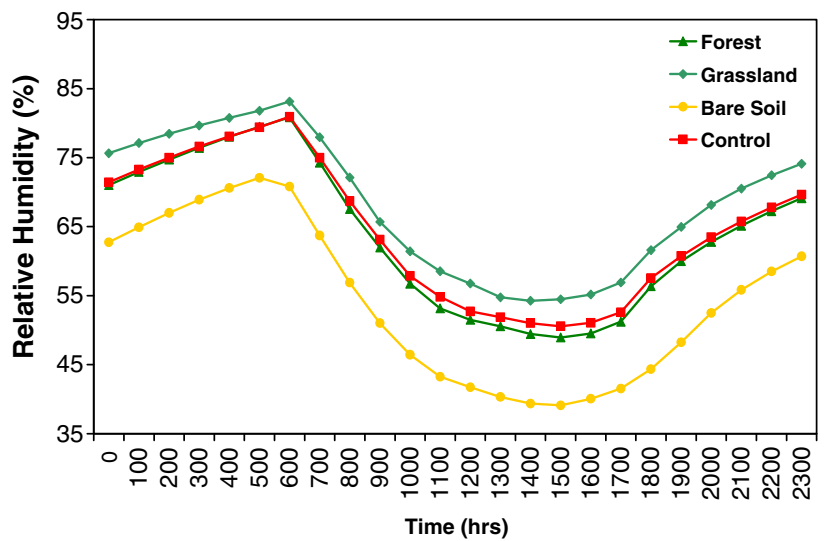

C

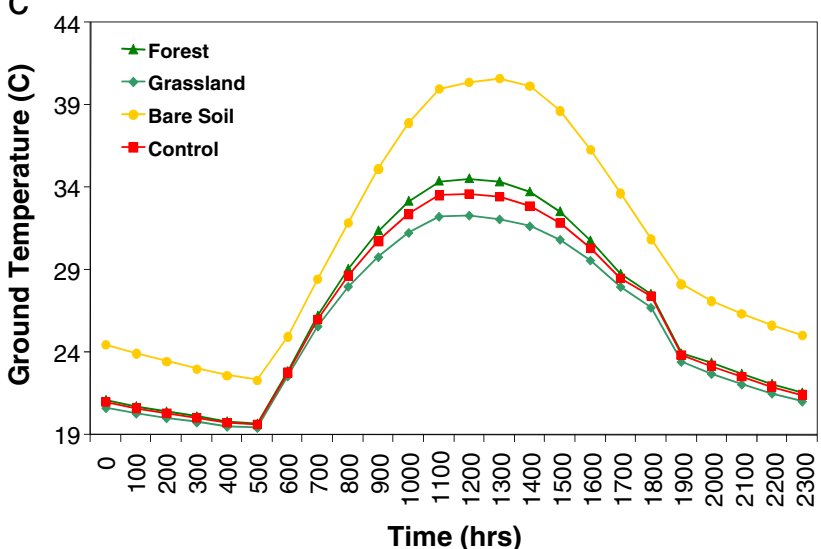

b

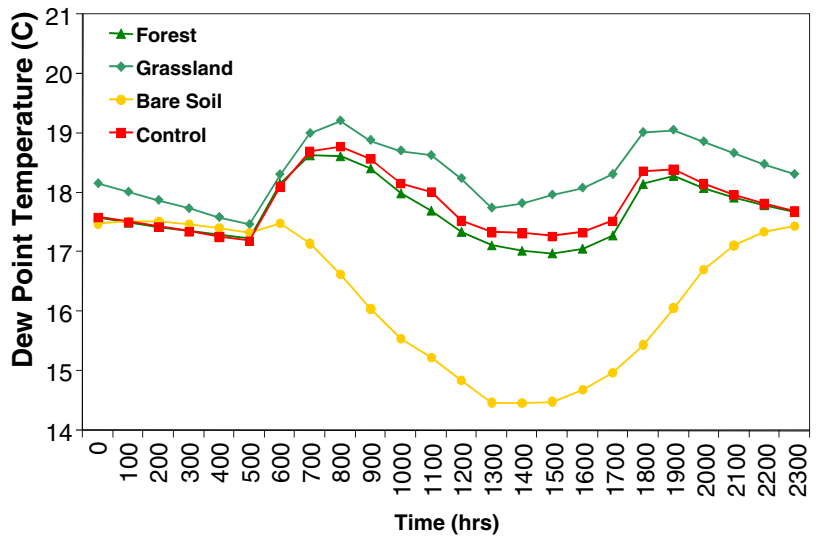

d

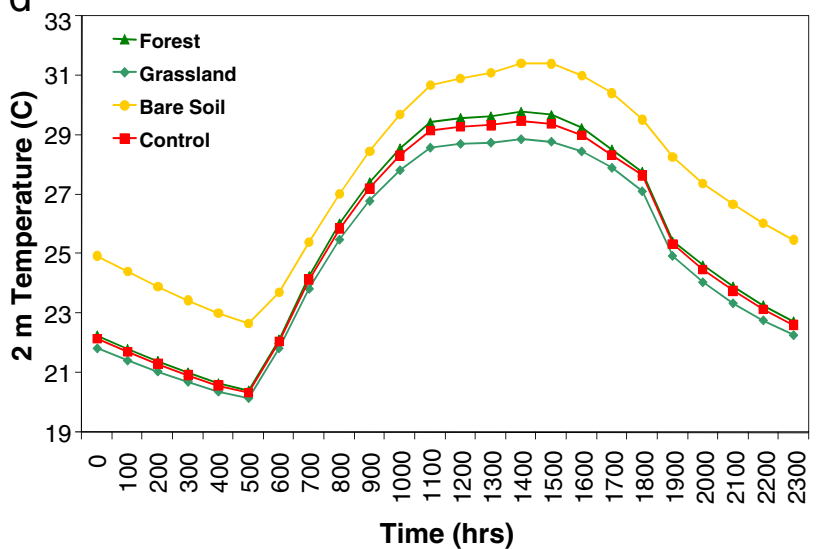

e

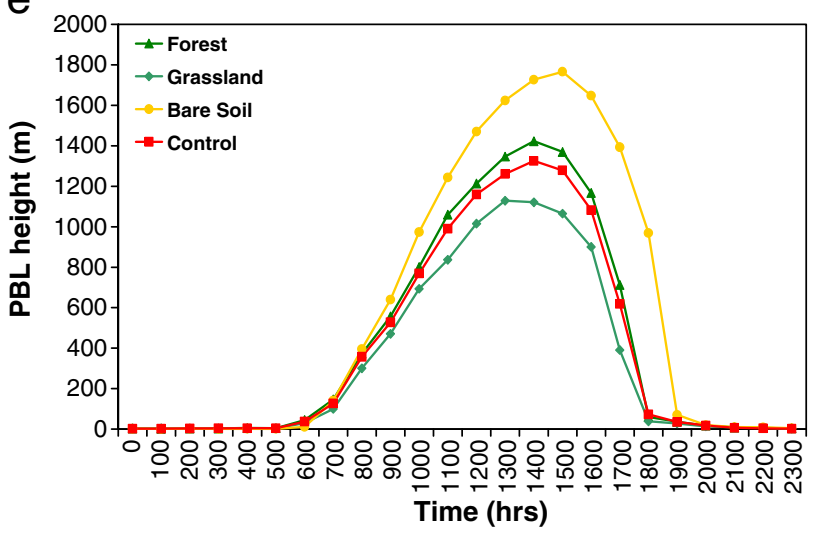

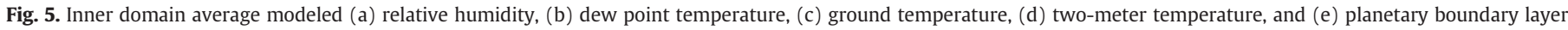
height for control, bare soil, grassland, and forest.

In addition, compared to CTRL, the average largest 24 hour increase in latent heat flux, relative humidity, and dew point temperature were $26 \mathrm{~W} \mathrm{~m}^{-2}, 5 \%$ and $0.78{ }^{\circ} \mathrm{C}$, respectively (Figs. $4 \mathrm{a}-\mathrm{b}$ and $5 \mathrm{a}-\mathrm{e}$ ). On the other hand, differences in sensible heat flux, ground surface and $2 \mathrm{~m}$ temperature, and PBL height showed decrease of $33 \mathrm{~W} \mathrm{~m}^{-2}, 1.35^{\circ} \mathrm{C}$, $0.60{ }^{\circ} \mathrm{C}$, and $228 \mathrm{~m}$, respectively. The increase in atmospheric moisture and relative cooling of ambient temperature can be largely attributed to lower stomatal resistance for grass and corresponding higher evapotranspiration. As a result, a small decrease in subsurface moisture was also noted (not shown).

Fig. 6a-f presents the differences in PBL height, wind fields, and equivalent potential temperature $\left(\theta_{e}\right)$ for grass, forest, and bare soil.
Here we discuss results from grass. In response to evaporation (latent heat flux) conducive environment, analysis of data indicates reduced PBL heights over the grass land use in comparison to CTRL. Fig. 6a shows that the largest reduction of PBL height was $300 \mathrm{~m}$ compared to CTRL with much of the domain exhibiting a reduction between 75 and $150 \mathrm{~m}$. Reduction in sensible heat flux (due increased latent heat flux) has also affected the horizontal wind field. It was found that divergence of wind away from the grassland.

Fig. $6 \mathrm{~b}$ shows elevated equivalent potential temperatures $\left(\theta_{e}\right)$ of $2{ }^{\circ} \mathrm{C}$ compared to CTRL simulations (Fig. 6b). These increases in $\theta_{e}$ (also known as moist static energy) over grassland land cover were in line with simulated increases in latent heat flux and atmospheric 
a

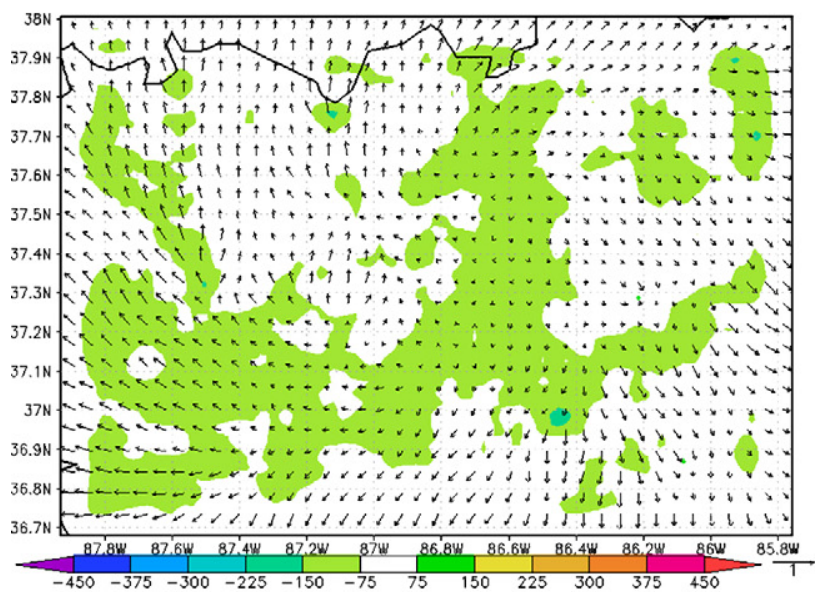

$\mathrm{C}_{38}$

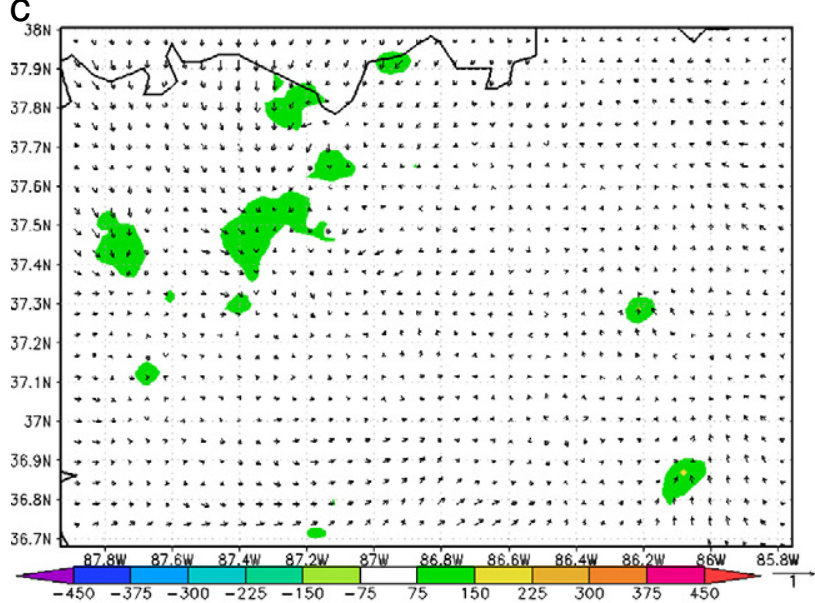

$\mathrm{e}_{38}$

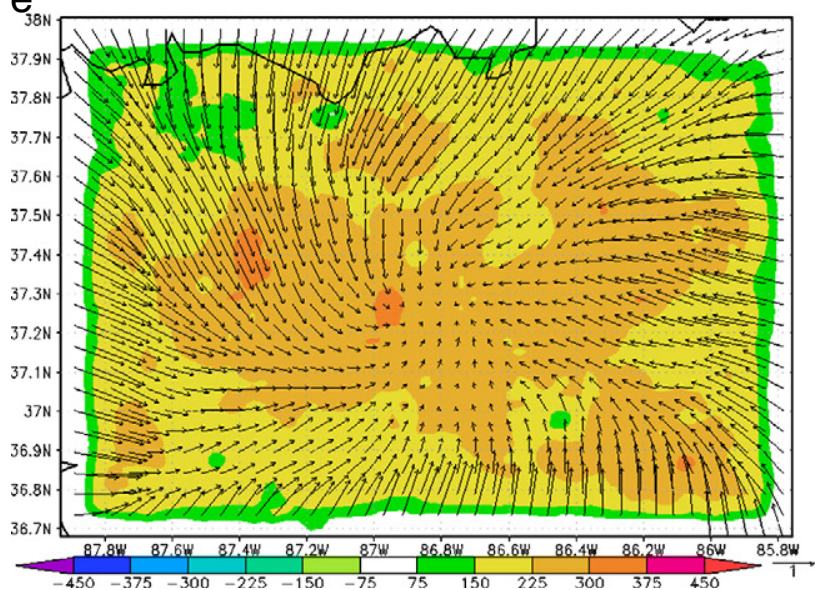

b

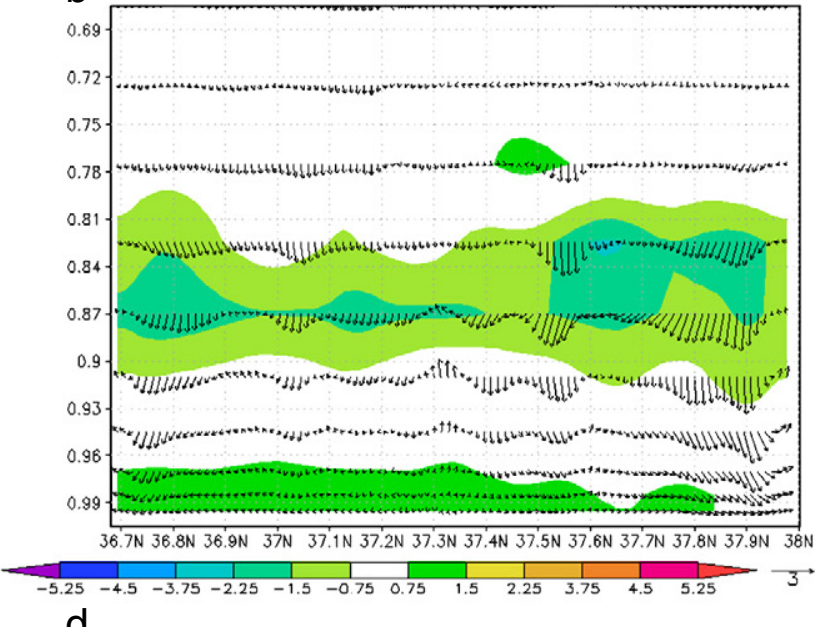

d

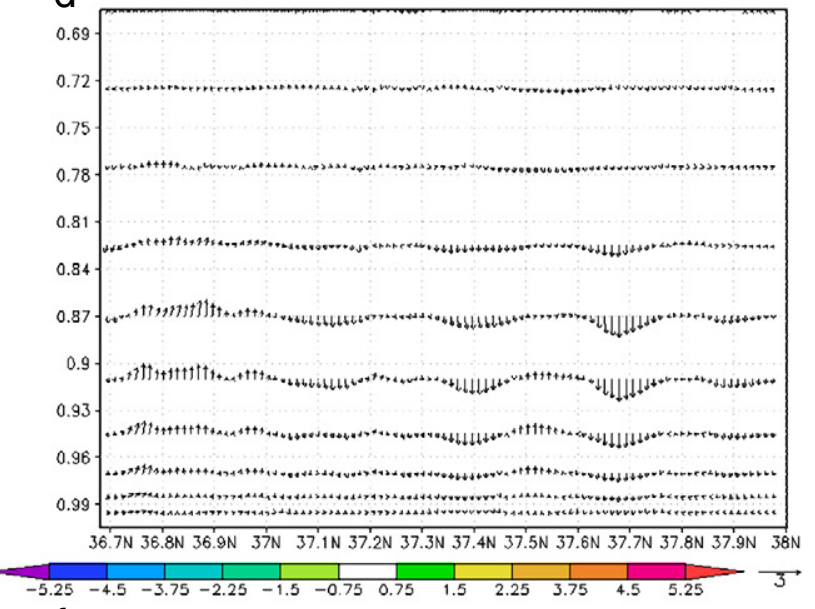

$f$

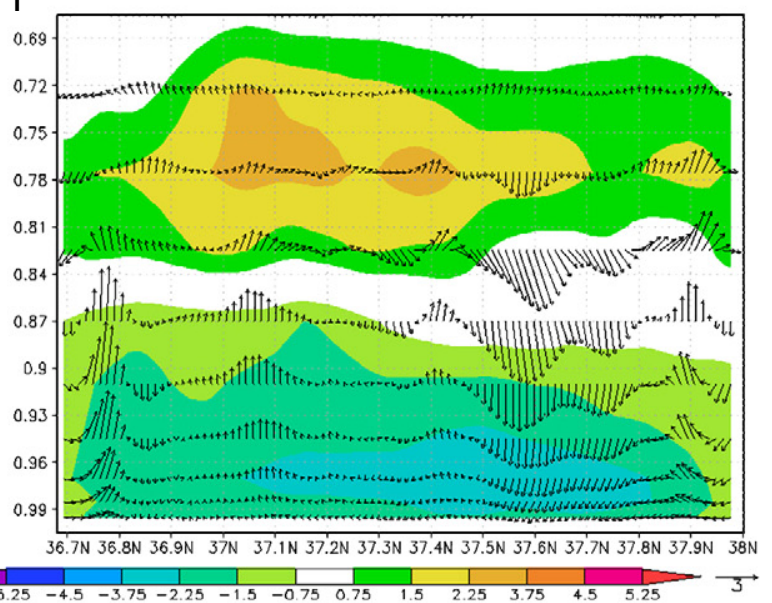

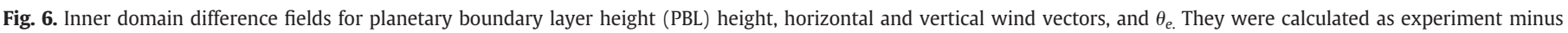

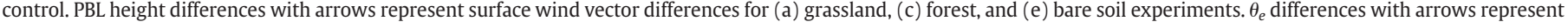
vertical wind vector differences for (b) grassland, (d) forest, and (f) bare soil.

moisture. The increase in simulated $\theta_{e}$ extended to the top of the grassland PBL near the $930 \mathrm{mb}$ level. However, the atmosphere became drier above this level. The cross section of vertical wind field analysis suggests primarily subsidence over the grassland region with maximum vertical wind speed differences near the simulated domain border in the order of $+2 \mathrm{~cm} \mathrm{~s}^{-1}$. It was also found that near-surface wind fields encountered increased surface roughness outside of the inner domain area and this potentially has increased drag-induced surface convergence and vertical motion just outside the region of LULCC (not shown). This ascending motion in turn resulted in subsidence near the grassland region as evident in Fig. 6b. Overall, this figure also indicates descending motions around inward edges of the grasslands (towards the center of inner domain) and ascending motions around outside edges of the grassland. In other words, two 

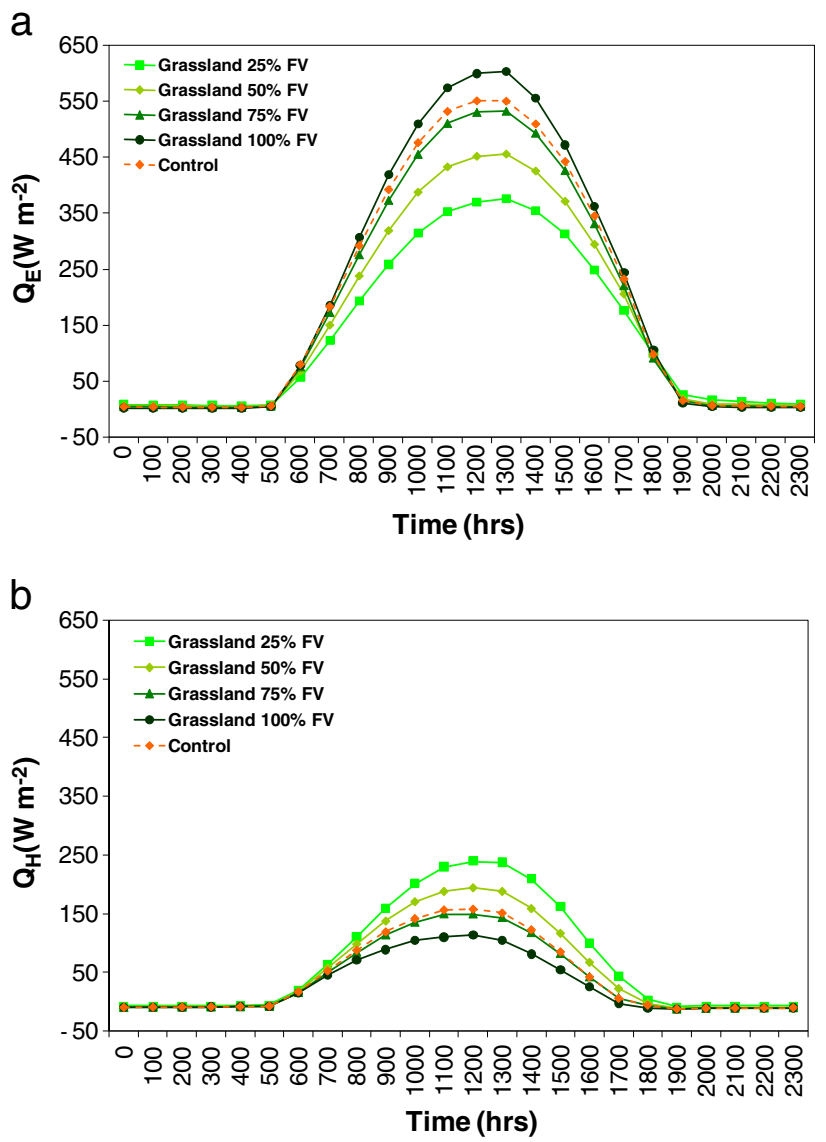

Fig. 7. Inner domain average modeled latent and sensible heat flux for control (dashed line) and grassland at $100,75,50$, and $25 \% \mathrm{FV}$.

distinct circulation cells were developed at the edges of grass land and this finding is similar to the findings of McPherson and Stensurd (2005). The present study has found lowering of PBL height and divergence in horizontal wind field which is also similar to the findings of McPherson and Stensurd (2005) and Segal et al. (1988).

\subsubsection{Combined impacts of land use induced land cover changes to grass} and vegetation fraction

We have already established in Section 1 that LULC and FV change impacts boundary layer structure. Scientific investigations largely treated these two changes separately. Sensitivity of PBL to combined systematic changes of the LULC and vegetation are not well investigated. This type of changes could present some interesting outcome. Conceptually we can deduce that reduction in FV can counteract the potential impacts of 'increase' in certain types of vegetation cover. For example, if we replace 'grass covered areas of high vegetation fraction' by 'forested areas with low vegetation fraction', evapotranspiration may decrease. The following sensitivity tests explore impacts of such potential changes.

Simulations for grassland were conducted systematically at 25,50 , 75 and $100 \%$ FV. Fig. 7a-b show simulated diurnal average latent and sensible heat fluxes for grass for various FVs. Partly due to the dynamic nature of the vegetation physiological response and absence of solar radiation, differences nearly disappear at night. Domain averages of latent heat flux were $140,166,189$, and $210 \mathrm{~W} \mathrm{~m}^{-2}$, respectively for these FVs (Table 4). In other words, replacement of 'forests with lower FV' by 'grass with higher FV' could replenish the reduced latent heat flux. As expected, domain average sensible heat fluxes decreased with increasing FV (Table 4). Ground surface, $2 \mathrm{~m}$ temperatures, and PBL heights were declined with increases in FV (Table 4). As the amount of green plant canopy increased (FV), atmospheric moisture increased proportionally and resulted in increased latent heat flux and lowering of PBL height.

The average largest 24 hour latent heat flux difference between grassland and CTRL (grass minus CTRL) were decreased by 180, 98, and $21 \mathrm{Wm}^{-2}$ at 25,50 , and $75 \% \mathrm{FV}$, respectively (Fig. 7a). However, there was an increase of $52 \mathrm{~W} \mathrm{~m}^{-2}$ for grassland at $100 \% \mathrm{FV}$ compared to CTRL. Similarly, the average largest 24 hour sensible heat flux increased as FV reduced from 100 to $25 \%$ (Fig. 7b). The average largest 24 hour relative humidity and dew point temperature difference showed decreases at 25, 50, and 75\% FV and increases at $100 \% \mathrm{FV}$, respectively (not shown). As expected, for ground surface and $2 \mathrm{~m}$ temperature, average largest 24 hour differences between grassland and CTRL increased at 25,50, and 75\% FV, and became cooler under $100 \%$ compared to CTRL.

The differences between grassland at 100, 75, 50, and 25\% FV and CTRL simulations indicate the PBL and surface wind fields were sensitive to these changes. Fig. 8a-h show how these are affected for each change in FV. As FV increased, PBL heights were reduced due to the reduction in sensible heat flux. At 100\% FV, PBL heights over grassland were up to $300 \mathrm{~m}$ lower in most location (Fig. 8a). However, these differences were diminished as FV was reduced. For example, PBL height differences between grassland and CTRL was reduced to up to less than $200 \mathrm{~m}$ for 75\% FV (Fig. 8c), but then grew larger than CTRL by 150 (Fig. 8e) and $300 \mathrm{~m}$ (Fig. 8g) at 50 and 25\% FV, respectively. As FV was reduced, the availability of subsurface moisture through the root zone was diminished and resulted in an increase in sensible heat flux and PBL heights. It needed be noted that a change in FV does not influence surface roughness length within the MM5. Therefore, the sensitivity of the PBL height to FV is really a sensitivity related to heat fluxes. Also, the horizontal surface wind field was more synchronized with PBL height than FV. As PBL heights increased with decreased FV (25 and 50\%) compared to CTRL simulations, horizontal surface wind converged over the grassland region (Fig. 8e and g). The reverse was true for increased FV.

Cross section analysis of $\theta_{e}$ differences between grassland at 100,75 , 50 and $25 \%$ FV show simulated varied responses in direction and magnitude of change compared to CTRL. At $100 \% \mathrm{FV}$, the grassland region largely showed increase of $\theta_{e}$ up to $2.25^{\circ} \mathrm{C}$ (Fig. 8b) at the lower part of the PBL while at $25 \% \mathrm{FV}$, modeled results showed reduction of up to $4{ }^{\circ} \mathrm{C}$ with respect to CTRL (Fig. $8 \mathrm{~h}$ ). Vertical wind field differences compared to CTRL also exhibited sensitivity to changes in FV. At $100 \% \mathrm{FV}$, much of the grassland region showed subsidence with wind speeds in the order of $2 \mathrm{~cm} \mathrm{~s}^{-1}$ greater than CTRL run (Fig. 8b). On the other hand, at $25 \% \mathrm{FV}$, vertical wind speed differences showed more areas with rising motion than subsidence with increasing vertical wind differences of $5 \mathrm{~cm} \mathrm{~s}^{-1}$ (Fig. 8h). Similar to other cross section analysis in this research, maximum vertical and horizontal wind fields were primarily located near the edges of LULCC border.

\subsubsection{Combined impacts of land use induced land cover changes to grass,} FV modifications and reduced soil moisture

Reductions in initial soil moisture compared to CTRL and under grassland at $25 \% \mathrm{FV}$ had a notable impact on simulated PBL processes. It

Fig. 8. Inner domain difference fields for modeled PBL height, horizontal and vertical wind vectors, and $\theta_{e}$. They were calculated as experiment minus control. PBL heights with arrows represent surface wind vector differences for grassland at: (a) 100 , (c) 75 , (e) 50 , and (g) $25 \%$ FV experiments. $\theta_{e}$ and arrows represent vertical wind vector differences for grassland at: (b) 100, (d) 75, (f) 50, and (h) $25 \%$ FV experiments. 
a

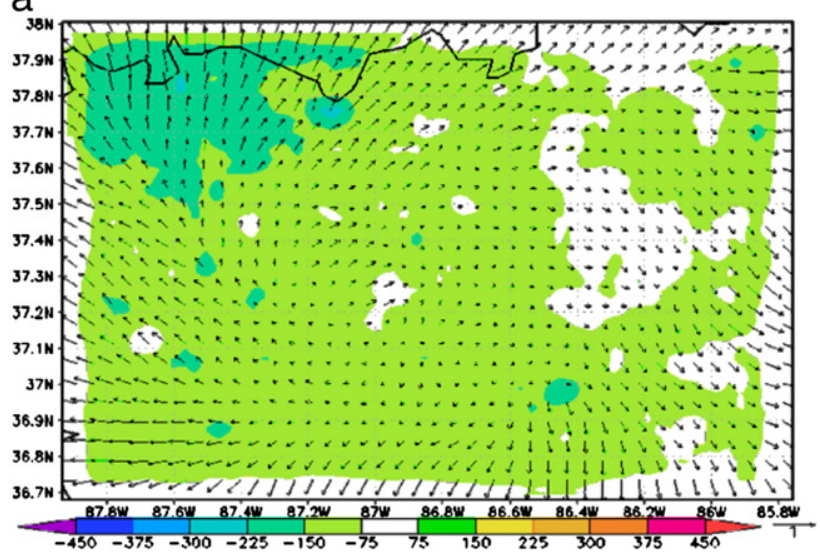

C

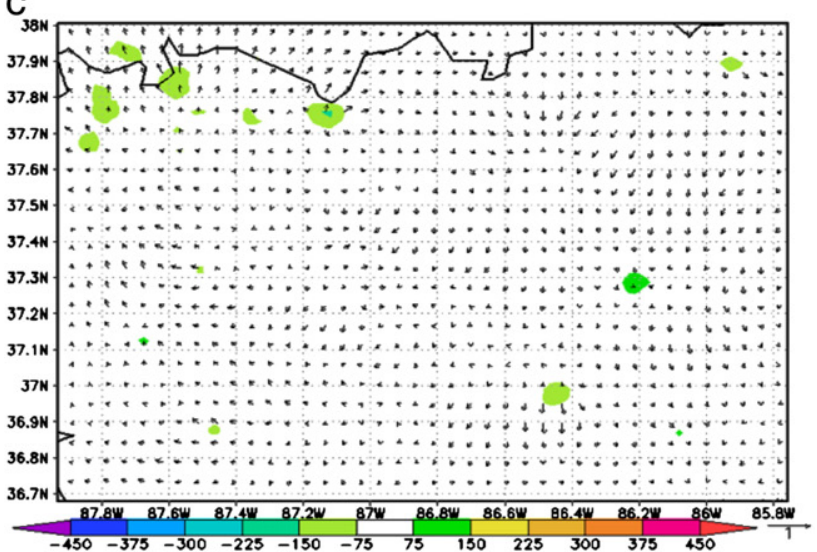

e

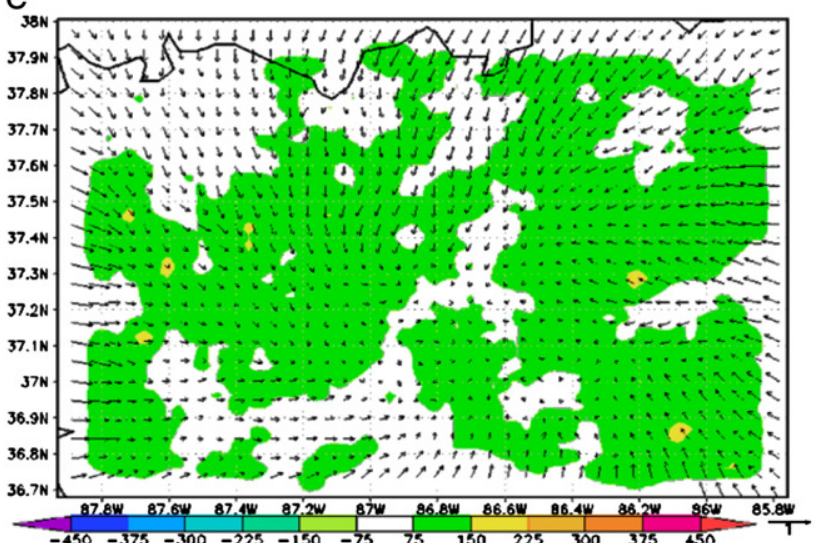

g

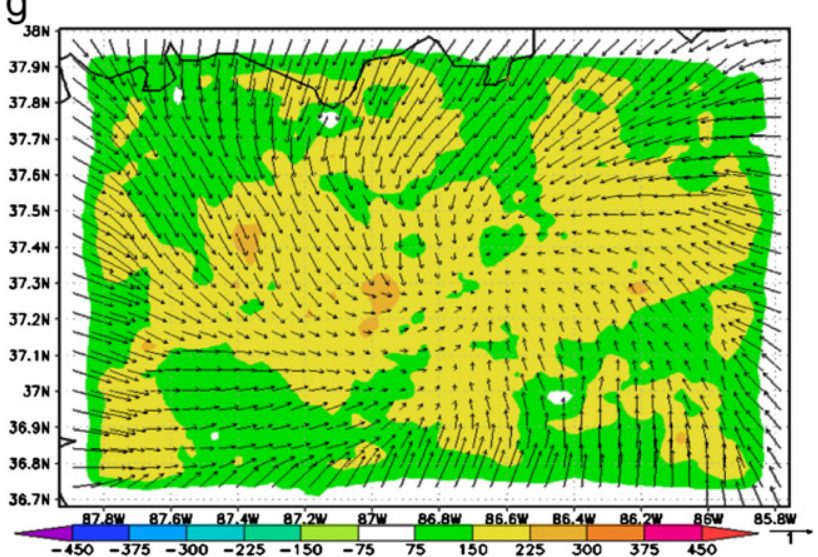

\section{b}

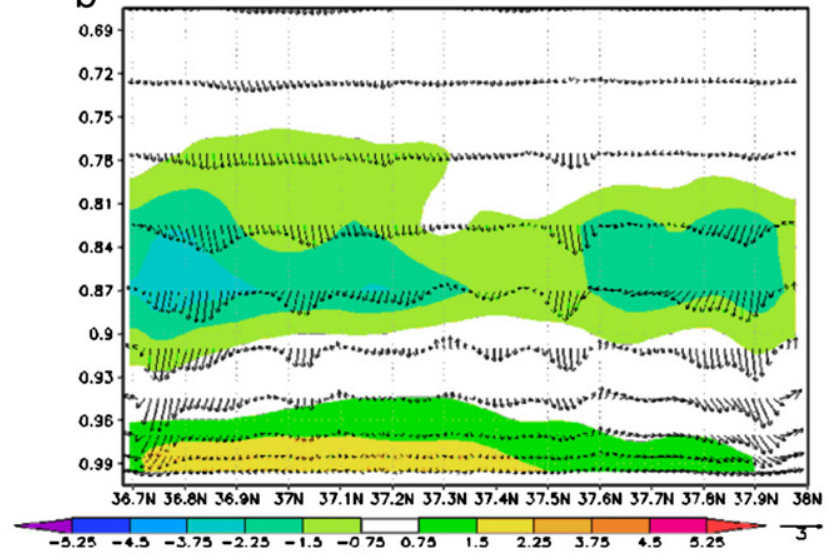

d

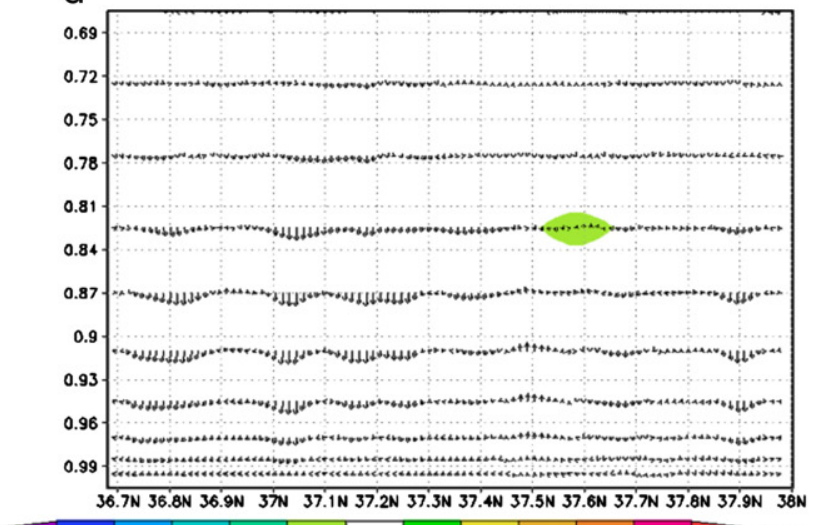

$\begin{array}{lllllllllllll}-5.25 & -4.5 & -3.75 & -2.25 & -1.5 & -0.75 & 0.75 & 1.5 & 2.25 & 3.75 & 4.5 & 5.25 & 3\end{array}$

f

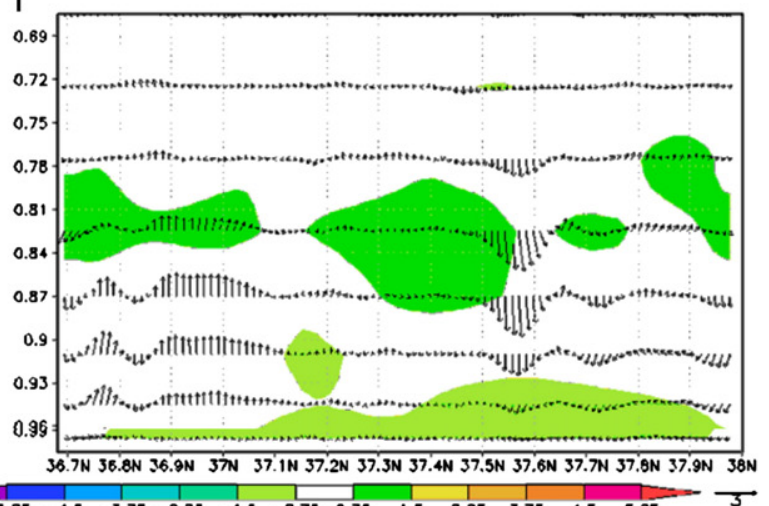

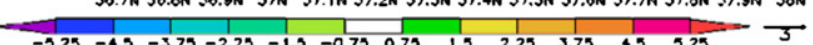

$\mathrm{h}$

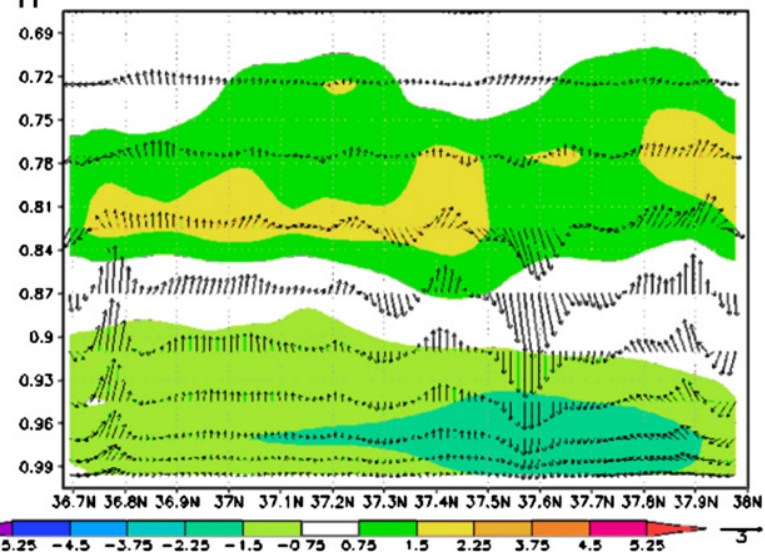



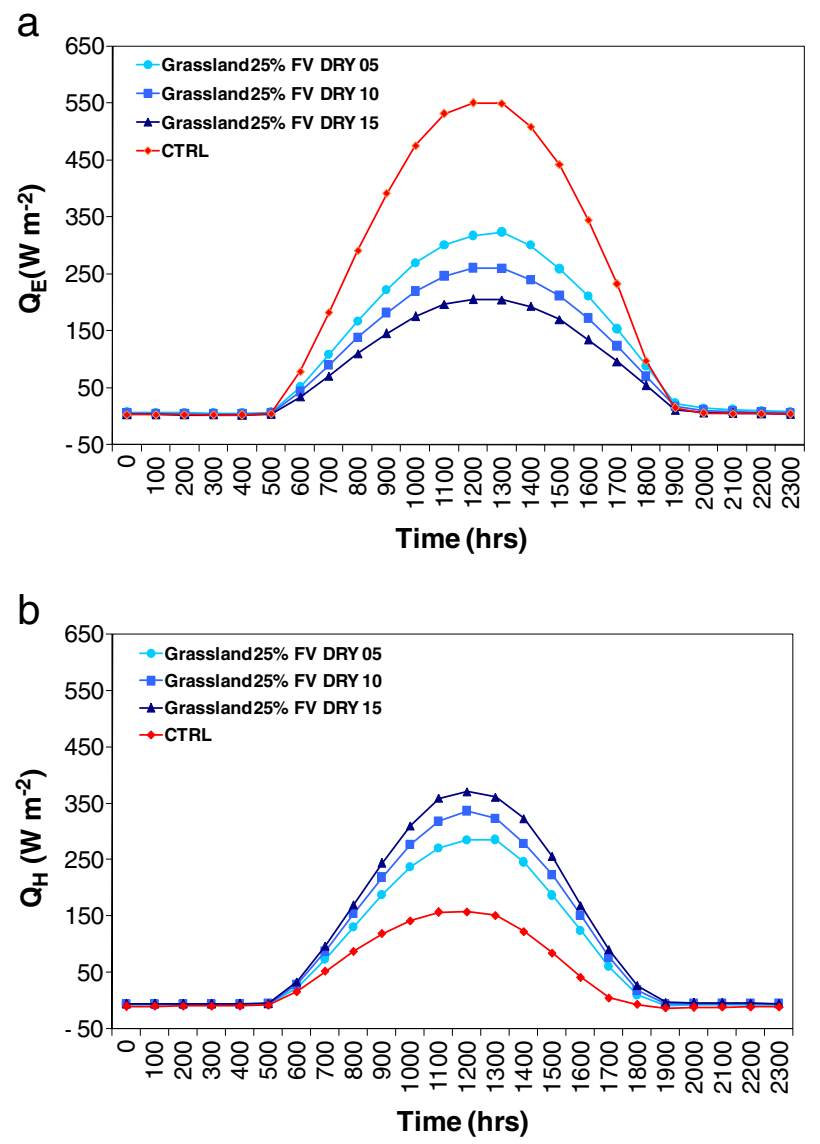

Fig. 9. Inner domain average modeled latent and sensible heat flux for control (solid line) and grassland at 25\% for DRY05, DRY10, and DRY15.

was found that surface fluxes were significantly altered with reduced soil moisture (Fig. 9a-b). Domain averages of latent heat flux were 120 , 91, and $76 \mathrm{~W} \mathrm{~m}^{-2}$ for DRY05, DRY10, and DRY15, respectively (Table 4). On the other hand, sensible heat fluxes were 85,101 , and $115 \mathrm{~W} \mathrm{~m}^{-2}$ for the same experiments, respectively. Relative humidity and dew point temperature were only slightly diminished. Given the lowering of latent heat flux for the dry grassland experiments one would expect a similar reduction in relative humidity and dew point temperature. However, it was not realized. Upon further analysis, results showed moisture convergence over the simulated domain due to shifts in horizontal surface wind fields. This is similar to the findings of Douville et al. (2001) and Sud and Smith (1985). Ground and $2 \mathrm{~m}$ temperatures and PBL height reported increase with drier soil moisture condition (Table 4).

Dry grassland experiments at $25 \% \mathrm{FV}$ with respect to CTRL were significantly drier and warmer and had higher PBL heights. The largest average 24 hour latent heat flux, dew point temperature, and relative humidity differences were less than CTRL (grassland minus CTRL) (Fig. 9a). Also, sensible heat flux, ground and $2 \mathrm{~m}$ temperatures, and PBL heights for the dry grassland experiments were considerably higher than CTRL.

Reductions in soil moisture for grassland at 25\% FV greatly enhanced turbulent mixing within the lower boundary layer causing PBL top to extend upward as described by Oke (1987). Moreover, Lifting Condensation Level (LCL) was raised 470 m under 25\% FV and DRY15 compared to CTRL (not shown). In other words, conditions for cloud development were changed. In addition, horizontal wind vector differences in comparison to CTRL were directed inward toward regions of higher PBL height (sensible heat flux) which is similar to Smith et al. (1994) findings. Maximum horizontal wind speed differences were greater than CTRL by 1,1 , and $1.4 \mathrm{~m} \mathrm{~s}^{-1}$ for each reduction in soil moisture.

Due to reductions in subsurface moisture, $\theta_{e}$ differences for the dry grassland experiments at $25 \% \mathrm{FV}$ varied between 2 and $5{ }^{\circ} \mathrm{C}$ less than CTRL within the lower boundary layer. Also, vertical wind field differences primarily showed rising motion for all dry grassland experiments at $25 \% \mathrm{FV}$ with circulations developed at both northern and southern edges. The development of land breezes along the vegetation boundaries has been described by Segal et al. (1988) and Ookouchi et al. (1984). They have attributed these circulations to sharp gradients in soil moisture found along the domain border. It was hypothesized that even over homogenous distributions of low $\mathrm{FV}$, land use thermal gradients may exist due to subtle elevation or soil moisture differences that give rise to preferential boundarylayer circulations (Smith et al., 1994). These circulations may have also developed due to vigorous mixing within the PBL for low FV experiments. Further research is necessary to assess this hypothesis. In additions, maximum vertical wind speed differences were greater than CTRL by 7,14 , and $15 \mathrm{~cm} \mathrm{~s}^{-1}$ for DRY05, DRY10, and DRY15, respectively.

The soil moisture-atmosphere feedback response to reductions in initial soil moisture over grassland at 50, 75, and 100\% FV were moderate when compared to simulated changes for grassland at $25 \% \mathrm{FV}$. Generally, direction of changes remained the same for all moisture, thermal, flux, wind, PBL height measures under all DRY scenarios (Table 4). However, at $100 \%$ FV, latent energy flux only became lower than CTRL when soil moisture was DRY15 (Fig. 10a). As a result, sensible heat flux remained lower than CTRL except DRY15 scenario (Fig. 10b). We find similar types of 'non-linearity' in $2 \mathrm{~m}$ temperature and PBL heights (Table 4). It is quite evident that increase in FV could notably reduce the impact of moisture deficit of soils and thus counter the impacts of drier soils. It should also be noted that as soil moisture was reduced, favorable locations for rising and subsiding motions has changed. In our opinion, it is an important finding. Progressive moderation of model sensitivity to higher FV has been previously noted by Chen and Avissar (1994). Similar results were found here even when we changed the soil moisture in combination with modification of FV. Hence, this is a further extension of Chen and Avissar's (1994) findings.

As noted by both Sud and Smith (1985) and Douville et al. (2001), reductions in soil moisture in some instances have been found to increase atmospheric moisture convergence over an area. Keeping in-line with these results, moisture flux was analyzed for both dry grassland experiments at $25 \% \mathrm{FV}$ and $100 \% \mathrm{FV}$ for the outer domain. Moisture flux represented by vectors indicated strong moisture convergence over dry grassland experiments for $25 \% \mathrm{FV}$ and a weak moisture divergence over dry grassland experiments for $100 \% \mathrm{FV}$. In addition, moisture flux for these experiments closely followed surface horizontal wind fields, which were perturbed by changes in PBL height.

\subsubsection{Forest}

Simulated differences between forested and CTRL were not too much dissimilar due to the fact that $74 \%$ of CTRL is forested. The domain average latent heat flux, relative humidity, and dew point temperature were decreased (forest minus CTRL) (Table 5) while there were increase in sensible heat flux and ground surface and $2 \mathrm{~m}$ temperature (Table 5), respectively. We suspect that these small increases, along with increases in surface roughness length, helped elevate PBL heights ( $30 \mathrm{~m}$ higher than CTRL).

Additional simulations were conducted to further understand forest's response with regard to latent heat flux. In this study the Noah LSM was not altered. LAI, as described by the MM5-Noah LSM, were identical (4.00) for grassland and forest. To address this issue, simulations were conducted using the Weather Research and Forecasting (WRF) model to obtain more realistic LAI values for forest (3.30) and 
a

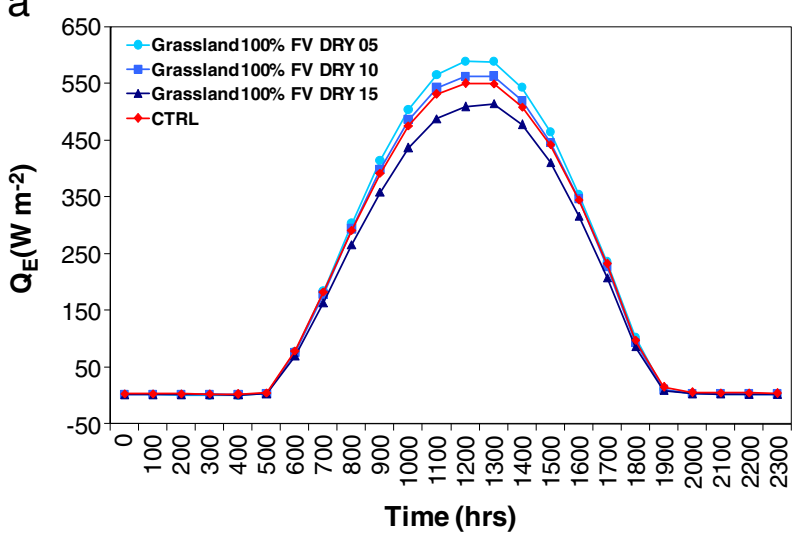

b

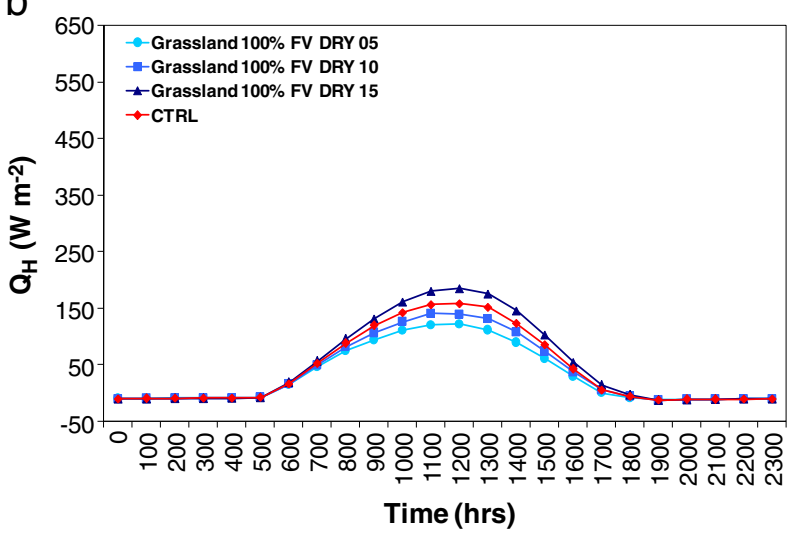

Fig. 10. Inner domain average modeled latent and sensible heat flux for control and grassland at $100 \%$ for DRY05, DRY10, and DRY15.

grass (2.92) [the difference is 0.38]. The WRF was used because it is essentially the next generation MM5. Subsequently, we have included these WRF estimated LAIs within the MM5 Noah LSM and conducted additional simulations. It was found that these changes had negligible impacts on the simulation of latent and sensible heat fluxes, air temperature, and relative humidity (Tables 6 and 7). However, given the uncertainty associated with all prescribed vegetation parameters in the

Table 5

Modeled inner domain area average estimates of selected variables for DRY forest experiments.

\begin{tabular}{lllllllll}
\hline $\begin{array}{l}\text { Land-use } \\
\text { and FV }\end{array}$ & SM & $\begin{array}{l}\text { Latent } \\
\text { heat } \\
\left(\mathrm{Wm}^{-2}\right)\end{array}$ & $\begin{array}{l}\text { Sensible } \\
\text { heat } \\
\left(\mathrm{Wm}^{-2}\right)\end{array}$ & $\begin{array}{l}\text { Rel. } \\
\text { humid. } \\
(\%)\end{array}$ & $\begin{array}{l}\text { Dew } \\
\text { point } \\
\left({ }^{\circ} \mathrm{C}\right)\end{array}$ & $\begin{array}{l}\text { Ground } \\
\text { temp. } \\
\left({ }^{\circ} \mathrm{C}\right)\end{array}$ & $\begin{array}{l}2 \mathrm{~m} \\
\text { Temp } \\
\left({ }^{\circ} \mathrm{C}\right)\end{array}$ & $\begin{array}{l}\text { PBL } \\
\text { height } \\
(\mathrm{m})\end{array}$ \\
\hline CTRL & CTRL & 198 & 42 & 64 & 17.7 & 25.0 & 25.9 & 401 \\
Forest & CTRL & 192 & 47 & 63 & 17.6 & 25.3 & 26.4 & 431 \\
FV 25\% & CTRL & 135 & 79 & 56 & 16.8 & 28.9 & 26.9 & 556 \\
& DRY05 & 116 & 92 & 54 & 16.3 & 29.7 & 27.3 & 600 \\
& DRY10 & 91 & 110 & 51 & 15.9 & 30.6 & 27.8 & 656 \\
& DRY15 & 67 & 125 & 49 & 15.5 & 31.3 & 28.3 & 705 \\
FV 50\% & CTRL & 158 & 67 & 58 & 17.0 & 28.0 & 26.3 & 520 \\
& DRY05 & 145 & 76 & 56 & 16.6 & 28.6 & 26.7 & 550 \\
& DRY10 & 124 & 90 & 53 & 16.1 & 29.4 & 27.1 & 603 \\
& DRY15 & 99 & 106 & 51 & 15.7 & 30.2 & 27.6 & 655 \\
FV 75\% & CTRL & 179 & 54 & 60 & 17.2 & 27.0 & 25.7 & 472 \\
& DRY05 & 172 & 60 & 59 & 16.9 & 27.5 & 26 & 507 \\
& DRY10 & 155 & 72 & 56 & 16.5 & 28.2 & 26.4 & 554 \\
& DRY15 & 131 & 89 & 53 & 16 & 29.1 & 29.6 & 614 \\
FV 100\% & CTRL & 199 & 42 & 65 & 17.9 & 26.1 & 25.1 & 404 \\
& DRY05 & 194 & 45 & 63 & 17.6 & 26.3 & 25.3 & 422 \\
& DRY10 & 182 & 54 & 60 & 17.1 & 27.0 & 25.7 & 473 \\
& DRY15 & 160 & 71 & 57 & 16.4 & 27.9 & 26.2 & 552 \\
\hline
\end{tabular}

Table 6

Grassland diurnal maximum and average differences for $\mathrm{LAI}=4.00$ minus $\mathrm{LAI}=2.92$. The percentages were calculated as the ratio of difference between a variable estimated based on original and new LAI and original LAI.

\begin{tabular}{lcccc}
\hline & $\begin{array}{l}\text { Latent heat } \\
\left(\mathrm{Wm}^{-2}\right)\end{array}$ & $\begin{array}{l}\text { Sensible heat } \\
\left(\mathrm{Wm}^{-2}\right)\end{array}$ & $\begin{array}{l}2 \mathrm{~m} \text { Tair } \\
\left({ }^{\circ} \mathrm{C}\right)\end{array}$ & $\begin{array}{l}\text { Relative } \\
\text { hum. }(\%)\end{array}$ \\
\hline $\begin{array}{l}\text { Ave. diff. } \\
\text { Ave. percent }\end{array}$ & 4.96 & -1.70 & -0.07 & 1.48 \\
$\quad$ \%) diff. & 2.44 & 5.09 & 0.29 & 2.18 \\
Max. diff. & 15.37 & -7.58 & -0.15 & 1.93 \\
$\begin{array}{l}\text { Percent } \\
\text { (\%) diff. }\end{array}$ & 2.66 & 5.94 & 0.52 & 2.32 \\
\hline
\end{tabular}

MM5 and the WRF (LAI, albedo, rooting depth, stomata resistance, and roughness length) we realize that the small difference is within the limits of uncertainty in the models.

It was found that diurnal averages of surface fluxes, $2 \mathrm{~m}$ temperature, and atmospheric moisture for the new LAI grass and forest experiments were quite similar to the original simulations. Moreover, slightly higher latent heat flux is reported again for grass.

In addition, the average difference of latent and sensible heat fluxes, $2 \mathrm{~m}$ temperature, and relative humidity between previous LAI and new LAI experiments (previous LAI minus new LAI) for grass was 4.96 and $-1.70 \mathrm{~W} \mathrm{~m}^{-2},-0.07{ }^{\circ} \mathrm{C}$, and $1.48 \%$, respectively (Table 6). These results were very similar to forest average differences for latent and sensible heat fluxes, $2 \mathrm{~m}$ temperature, and relative humidity of 4.66 and $-1.20 \mathrm{Wm}^{-2},-0.02{ }^{\circ} \mathrm{C}$, and $0.74 \%$, respectively, between previous LAI and new LAI experiments (Table 7). Moreover, the largest diurnal difference of latent and sensible heat fluxes, $2 \mathrm{~m}$ temperature, and relative humidity between previous LAI and new LAI experiments (previous LAI minus new LAI) for grass was 15.37 and $-7.58 \mathrm{Wm}^{-2},-0.15^{\circ} \mathrm{C}$, and $1.93 \%$, respectively (Table 6 ). These results were also very similar to forest largest diurnal differences for latent and sensible heat fluxes, two meter temperature, and relative humidity of 16.53 and $-7.97 \mathrm{~W} \mathrm{~m}^{-2},-0.12{ }^{\circ} \mathrm{C}$, and $1.03 \%$, respectively, between previous LAI and new LAI experiments (Table 7).

The changes in surface fluxes, temperature, and atmospheric moisture between grass and forest previous and new LAI experiments were small and that distinguishing difference between model noise and signal was difficult. In addition, simulated changes for grass and forest LAI experiments were nearly the same, which would cancel each other and preserve the grass ET advantage over forests. In other words, given the uncertainty associated with all prescribed vegetation parameters in the MM5 and the WRF (LAI, albedo, rooting depth, stomata resistance, and roughness length) we realize that the small difference was within the limits of uncertainty of the model. Moreover, LAI alone does not explain the moist/cool bias over grasses compared to forest in study. Finally, there is no scientifically accepted one LAI value for grass or forest. Observational methods and techniques to compute LAI from ground measurements and satellites have come a long away, but are still being actively refined. Given the uncertainty and difficulty in observing LAI and the limited impact it had on model results, it was felt that altering the look-up table was beyond the scope of this study and not warranted.

Table 7

Forest diurnal maximum and average differences for $\mathrm{LAI}=4.00$ minus $\mathrm{LAI}=3.30$. The percentages were calculated as the ratio of difference between a variable estimated based on original and new LAI and original LAI.

\begin{tabular}{lcccc}
\hline & $\begin{array}{l}\text { Latent heat } \\
\left(\mathrm{Wm}^{-2}\right)\end{array}$ & $\begin{array}{l}\text { Sensible heat } \\
\left(\mathrm{Wm}^{-2}\right)\end{array}$ & $\begin{array}{l}2 \mathrm{~m} \text { Temp. } \\
\left({ }^{\circ} \mathrm{C}\right)\end{array}$ & $\begin{array}{l}\text { Relative } \\
\text { hum. }(\%)\end{array}$ \\
\hline Ave. diff. & 4.66 & -1.20 & -0.02 & 0.74 \\
Ave. percent & 2.42 & 2.55 & 0.08 & 1.17 \\
$\begin{array}{l}\text { (\%) diff. } \\
\text { Max. diff }\end{array}$ & 16.53 & -7.97 & -0.12 & 1.03 \\
$\begin{array}{l}\text { Percent } \\
\text { (\%) diff. }\end{array}$ & 3.11 & 4.54 & 0.42 & 1.27 \\
& & & &
\end{tabular}


Furthermore, resistance to ET also helps to explain the evaporative advantage of grass over forest found in this study. Following Oke (1987) and assuming a big leaf approach, resistance to transpiration for a region can be broken down into canopy resistance $\left(r_{c}\right)$ and aerodynamic resistance $\left(r_{a}\right)$. Canopy resistance is a function of physiological features (such as stomata) that regulate transpiration with aerodynamic resistance a function of atmospheric turbulent effect on transpiration (such as wind speed and surface roughness). From Oke (1987; pg 127) the canopy resistance for grass $\left(\sim 70 \mathrm{~s} \mathrm{~m}^{-1}\right)$ is less than forests $(\sim 80-$ $\left.150 \mathrm{~s} \mathrm{~m}^{-1}\right)$. However, because forests have a greater roughness length and generate more turbulence $r_{a}$ for forests $\left(\sim 5-10 \mathrm{~s} \mathrm{~m}^{-1}\right)$ is much smaller than grass $\left(\sim 70 \mathrm{~s} \mathrm{~m}^{-1}\right)$. These values were estimated based on $2 \mathrm{~m}$ wind speeds at $3 \mathrm{~ms}^{-1}$. As a result, the total resistance for forest land cover is typically less than grass, which would result in greater ET. The Noah LSM allows resistance to vary dynamically over time based on the Jacquemin and Noilhan (1990) approach. For the period considered in this study near surface winds were weak. Maximum modeled $10 \mathrm{~m}$ wind speed for CTRL's inner domain during the last 7 days of the experiment was $5.5 \mathrm{~ms}^{-1}$ with a maximum average wind speed of $3.5 \mathrm{~ms}^{-1}$. It is well known that wind speeds decrease further near the surface and thus it is safe to assume that $2 \mathrm{~m}$ wind speeds are much less than $3 \mathrm{~ms}^{-1}$ and hence reduced the impact of turbulent mixing on simulated ET. Moreover, in the context of atmospheric conditions on simulated ET it is reasonable to assume that grasses would have a small ET advantage over forests. Simulated latent heat flux differences between grass land cover and forest were only $10 \mathrm{Wm}^{-2}$. Again, this is a very small change and is less than the internal variability of the model.

The average largest 24 hour reduction in modeled latent heat flux was $21 \mathrm{Wm}^{-2}$ compared to CTRL (Fig. 4a). The differences (forest minus (TRL) in atmospheric moisture for simulated forested areas were modest compared to CTRL (Fig. 5b and e). Overall, results suggest that forest land use modified near surface moisture content. However, compared to grass, the magnitudes of these changes were muted.

The maximum PBL height differences were in the range of 150$200 \mathrm{~m}$ shown in Fig. 6c. However, most of the forested region showed increases in PBL height of less than $100 \mathrm{~m}$. Horizontal wind field differences indicated weak convergence over the forest region linked to both the slight increase in PBL height and increase in surface roughness. This is similar to the suggestion of McPherson and Stensurd (2005) that the first order differences were attributed to the changes in PBL height. Maximum horizontal surface wind speed differences (forest minus CTRL) in the order of $+0.3 \mathrm{~cm} \mathrm{~s}^{-1}$ were concentrated over the northwestern corner and along the forested edge of the domain. This is likely the result of the larger forest PBL height difference with respect to CTRL.

The vertical cross sectional analysis of $\theta_{e}$ reveals almost no simulated difference between forest and CTRL runs (Fig. 6d). These results are in agreement with other simulated atmospheric fields between forest and CTRL.

\subsubsection{Combined impacts of land use induced land cover changes to forest} and FV modifications

As expected, again, increase in forest FV enhanced moisture content in the planetary boundary layer (Table 8 ). On the other hand, sensible heat fluxes were decreased. Ground surface and $2 \mathrm{~m}$ temperatures reported decline with increasing FV. Domain average PBL heights were 556, 520, 472, and $404 \mathrm{~m}$ for the above FV categories, respectively. Overall, there were systematic changes to planetary boundary layer variables in response to FV changes and they are consistent with our theoretical understanding.

The average largest 24 hour difference between forest and CTRL FV were decreased with increased FV (Fig. 11a). In addition, with increasing FV resulted in decrease in sensible heat fluxes (Fig. 11b). Dew point temperatures also increased and the differences declined. PBL height sensitivity to changes in $100 \%$ FV was less over forest than
Table 8

Modeled inner domain area average estimates of selected variables for DRY bare soil experiments.

\begin{tabular}{lllllllll}
\hline Land-use & SM & $\begin{array}{l}\text { Latent } \\
\text { heat } \\
\left(\mathrm{Wm}^{-2}\right)\end{array}$ & $\begin{array}{l}\text { Sensible } \\
\text { heat } \\
\left(\mathrm{Wm}^{-2}\right)\end{array}$ & $\begin{array}{l}\text { Rel. } \\
\text { humid. } \\
(\%)\end{array}$ & $\begin{array}{l}\text { Dew } \\
\text { point } \\
\left({ }^{\circ} \mathrm{C}\right)\end{array}$ & $\begin{array}{l}\text { Ground } \\
\text { temp. } \\
\left({ }^{\circ} \mathrm{C}\right)\end{array}$ & $\begin{array}{l}2 \mathrm{~m} \\
\text { temp. } \\
\left({ }^{\circ} \mathrm{C}\right)\end{array}$ & $\begin{array}{l}\text { PBL } \\
\text { Height } \\
(\mathrm{m})\end{array}$ \\
\hline CTRL & CTRL & 198 & 42 & 64 & 17.7 & 25.0 & 25.9 & 401 \\
Bare soil & CTRL & 99 & 79 & 54 & 16.2 & 30.4 & 27.3 & 588 \\
& DRY05 & 77 & 94 & 51 & 15.8 & 31.4 & 27.8 & 642 \\
& DRY10 & 52 & 113 & 49 & 15.4 & 32.3 & 28.3 & 702 \\
& DRY15 & 31 & 129 & 47 & 15.1 & 33.2 & 28.7 & 760 \\
\hline
\end{tabular}

grassland when compared to CTRL (Fig. 12a). Overall, horizontal surface wind field differences were relatively small (approximately $0.5 \mathrm{~cm} \mathrm{~s}^{-1}$ ). However, surface wind speeds were higher near regions with the greater change in PBL height compared to CTRL. As vegetation fraction reduced to 75,50 , and $25 \%$, forest PBL height responded with heights greater than CTRL by 150,225 , and $300 \mathrm{~m}$ in most areas, respectively (Fig. 12c, e and g). Horizontal surface wind speed differences also increased with PBL height changes..

Cross section analysis reveals that forest at $100 \% \mathrm{FV}$ is the only 'forest' model run with increases in $\theta_{e}$ up to $0.4{ }^{\circ} \mathrm{C}$ compared to CTRL. As FV reduced to 75,50 , and $25 \%$, areas with $\theta_{e}$ decrease up to $1.5^{\circ} \mathrm{C}$ compared to CTRL also grew notably (Fig. $12 \mathrm{~b}, \mathrm{~d}$, f, and $\mathrm{h}$ ). These findings are in agreement with previous results of this study which showed a reduction in simulated atmospheric moisture over forest regions as FV was reduced. Modeled vertical wind fields over the forest region at 100\% FV show both rising and subsiding air columns throughout the forest region. Compared to CTRL, rising motion became predominant as FV was reduced. Vertical wind speeds at $100,75,50$, and $25 \%$ FV were greater
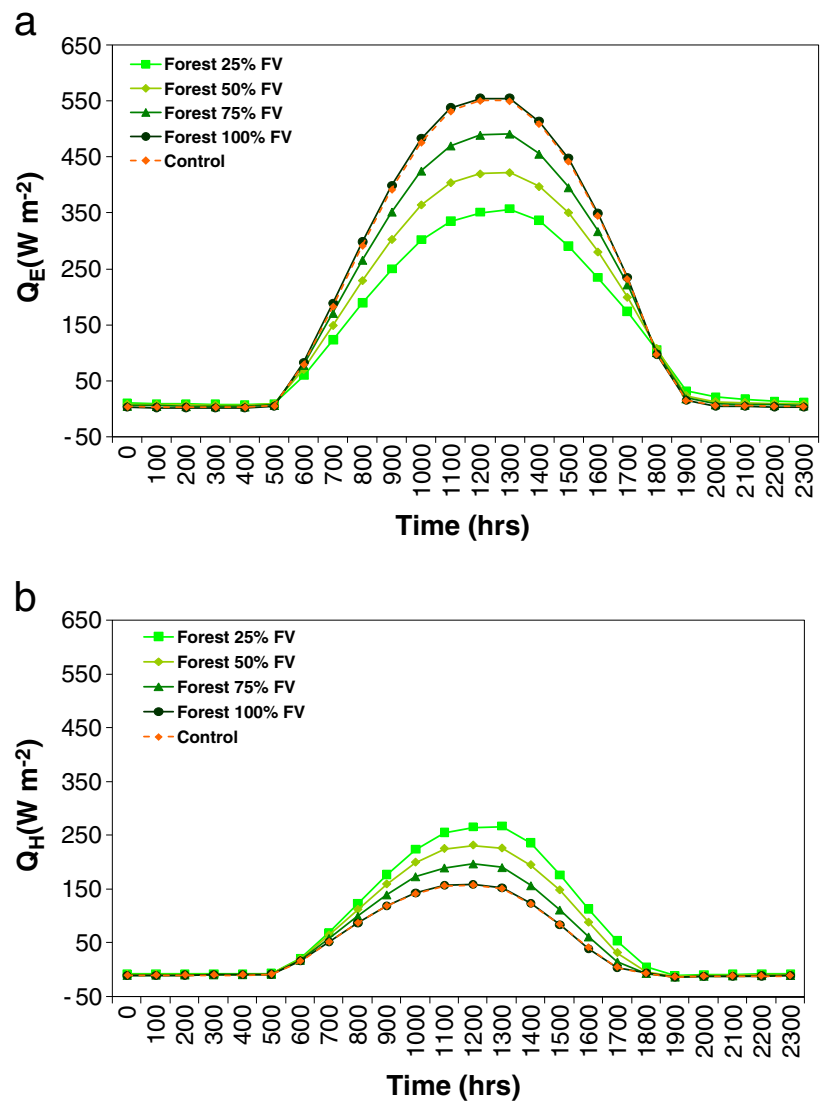

Fig. 11. Inner domain average modeled latent and sensible heat flux for control and forest at $100,75,50$, and $25 \% \mathrm{FV}$ experiments. 
than CTRL by $0.8,3,5$, and $6 \mathrm{~cm} \mathrm{~s}^{-1}$, respectively. Please recall, that both horizontal and vertical fields are directly impacted by changes in PBL height as FV has an indirect pathway to affect modeled wind fields.

As previously described, changing of land use land cover and FV both influence modeled total evapotranspiration. It is possible that changes in land use and vegetation could result in decreased evapotranspiration. However, this could be reversed by enhanced FV. In other words, combined impact of FV and LULCC may cancel or enhance overall simulated results for various components of hydrologic cycle. In our opinion, it is an important finding.

Findell and Eltahir (2003) identified two pathways in which changes in land use can initiate convection. Over dryer land surfaces, the increase in sensible heat flux and the subsequent rise of the PBL in a way so that the PBL reaches the level of free convection (LFC) and thus generating convective activities. On the other hand, over moist land surfaces the increase in moist static energy may lower the LFC to the PBL height, and generating convection. Lyons (2002) also observed the development of convectively generated clouds only over dry native vegetation than the more moist adjacent agricultural fields. He attributed the development of these clouds as a result of the high PBL heights over the native land cover. The present study is set under a stable synoptic condition. However, based on the findings of Findell and Eltahir (2003) and Lyons (2002), it could be suggested that the changes in PBL heights due to modification of LULC and FV has also changed the potential for convective development.

3.2.6. Combined impacts of land use induced land cover changes to forest, FV modifications and reduced soil moisture

Simulated surface fluxes for forest land use at 25\% FV were highly sensitive to reductions in initial soil moisture. Low FV resulted in low evapotranspiration. Domain average of latent and sensible heat fluxes were 116, 91, and 67, and 92, 110, and $125 \mathrm{~W} \mathrm{~m}^{-2}$ for DRY05, DRY10, and DRY15, respectively (Table 5 ). At the same time relative humidity and dew point temperatures were declined while ground and $2 \mathrm{~m}$ temperatures and PBL height were elevated.

In comparison to CTRL, as expected, dry forest experiments at $25 \% \mathrm{FV}$ were significantly drier and warmer with elevated PBL heights. The largest 24 hour average latent heat flux, relative humidity, and dew point temperature differences were much less than CTRL while sensible heat flux, ground and $2 \mathrm{~m}$ temperatures, and PBL height were greater.

PBL height and horizontal wind field differences with respect to CTRL revealed their sensitivity to reductions in subsurface moisture. PBL height differences varied across the domain (not shown here) due to randomly generated turbulent eddies as described by Chen and Avissar (1994) which lead to greater PBL growth. The simulations also suggest increase in LCL height up to $512 \mathrm{~m}$ compared to CTRL under 25\% FV and DRY15 scenario and it is greater than grass land use under similar conditions (not shown). Horizontal wind field differences directed toward the domain center increased as soil moisture was reduced. Maximum horizontal wind speed differences were greater than CTRL by $0.6,0.8$, and $1.4 \mathrm{~ms}^{-1}$ for DRY05, DRY10, and DRY15, respectively.

A cross section of $\theta_{e}$ differences showed its reduction compared to CTRL with drier soils. For the dry forest experiments at $25 \% \mathrm{FV}, \theta_{e}$ differences within the lower boundary layer (up to $850 \mathrm{mb}$ ) ranged between 2 and $5{ }^{\circ} \mathrm{C}$ less than CTRL. Similar to dry grassland experiments at $25 \% \mathrm{FV}$, meso-scale circulations developed both along the cross section and the northern and southern edges. Along the cross section, it was found that with reductions in soil moisture maximum vertical wind speed differences increased with drier soil moisture. Again, response to reductions in initial soil moisture over forest at 50,75 , and $100 \%$ FV were muted when compared to simulated changes for forest at $25 \% \mathrm{FV}$. Generally, direction of changes remained the same for all moisture, thermal, flux, wind, PBL height measures under DRY05, DRY10, and DRY15 (not shown).
However, as opposed to grass, latent heat flux remained lower for all DRY scenario under 100\% FV forest LULC. For the same FV and LULC scenario, $2 \mathrm{~m}$ temperature remained lower for DRY05 and DRY10 compared to CTRL. While for the grass $2 \mathrm{~m}$ temperature remained lowered compared to CTRL for all DRY scenario. PBL heights were higher compared to CTRL for all DRY scenarios for 100\% FV for forest. On the other hand, for grass these heights were lower compared to CTRL for DRY05 and DRY10 scenario for $100 \%$ FV. Overall, compared to forest, grass LULC resulted in relatively more moist and cooler near surface atmosphere and lower PBL heights. LCL heights were raised further for forest compared to grass. In other words, historical (grassland) and recent (forest) LULCC modified PBL characteristics for these time periods.

\subsubsection{Bare soil}

It could be inferred from table 8 that there were $99 \mathrm{Wm}^{-2}, 10 \%$, $1.5{ }^{\circ} \mathrm{C}$ decrease (bare soil minus CTRL) in latent heat flux, relative humidity, dew point temperature, respectively. On the other hand, compared to CTRL simulation, there were $37 \mathrm{Wm}^{-2}, 5.4$, and $1.4{ }^{\circ} \mathrm{C}$ increase in sensible heat flux, ground surface and $2 \mathrm{~m}$ temperature, respectively.

The average largest 24 hour differences (bare soil minus CTRL) suggests $13 \%$ and $2.9{ }^{\circ} \mathrm{C}$ lowering of relative humidity and dew point temperatures (Fig. 5b, e), respectively. It makes sense because it is already shown above that the modeled latent and sensible heat flux over bare soil were about 303 and $111 \mathrm{Wm}^{-2}$ lower and higher compared to CTRL simulations, respectively (Fig. 4). This is also in line with the simulated warmer temperatures and a higher PBL height compared to CTRL. The PBL height for bare soil was $1750 \mathrm{~m}$.

Impacts of LULCCs were most prominent between mid-morning to mid-afternoon hours. For example, latent heat flux from CTRL, grass, forest, and bare soil during noon were 551, 577, 555, and $254 \mathrm{Wm}^{-2}$, respectively (Fig. 4a). The differences in latent and sensible heat flux, planetary boundary layer height, and dew point temperatures for CTRL, grass, forest, and bare soil were nearly completely diminished during evening hours as can be seen in Figs. 4a-b and 5b and e.

The largest seven day average increase in PBL height was $550 \mathrm{~m}$. Similar to findings in other research, increases in sensible heat flux is thought to be the main contributing factor leading to elevated PBL heights (e. g., McPherson and Stensurd, 2005). As a result of the increase in PBL height over bare soil, surface horizontal wind fields were directed inward in comparison to CTRL (Fig. 6e). Maximum wind speed differences were up to $1 \mathrm{~ms}^{-1}$, but spatially confined along a narrow band near the domain border. This is partly due to the reduction in surface roughness. The increase in wind speed was then entrained to the ascending motion, evident in simulated vertical velocities. It was also found that the largest increase in differences in vertical velocities were near the domain border.

A cross section analysis indicates the vertical extent of the bare soil region's forcing on the vertical structure of the atmosphere (Fig. 6f). $\theta_{e}$ differences between bare soil and CTRL indicated lower $\theta_{e}$ over bare soil by as much as $6{ }^{\circ} \mathrm{C}$ near the surface and up to $1{ }^{\circ} \mathrm{C}$ at the $870 \mathrm{mb}$ level. The LULCC also initiated higher vertical velocities and horizontal wind speeds near the domain border. Maximum vertical speed differences of $+4 \mathrm{~cm} \mathrm{~s}^{-1}$ were estimated.

In summary, latent heat flux was higher over grass due to lower model assigned stomatal resistance. On the other hand, bare soil reported higher sensible heat flux. It was also found that relative humidity and dew point temperatures were the highest under grass land use and the lowest under bare soil. In addition, bare soil reported the highest $2 \mathrm{~m}$ and ground temperature and planetary boundary layer height. Conversely, these estimates were the lowest for grass land use. Moreover, LULCC changed meso-scale wind field of the PBL. Thus, land use change has certainly affected characteristics of the planetary boundary layer. 
$\mathrm{a}_{38}$

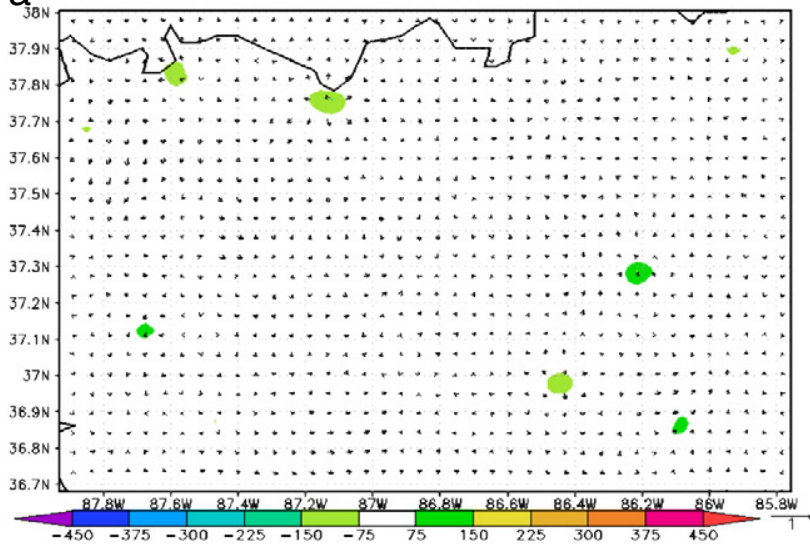

C

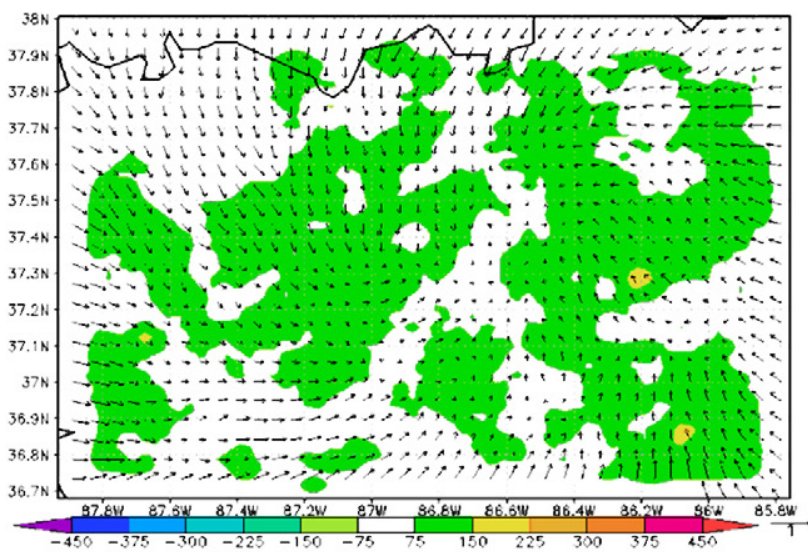

$\mathrm{e}_{38}$

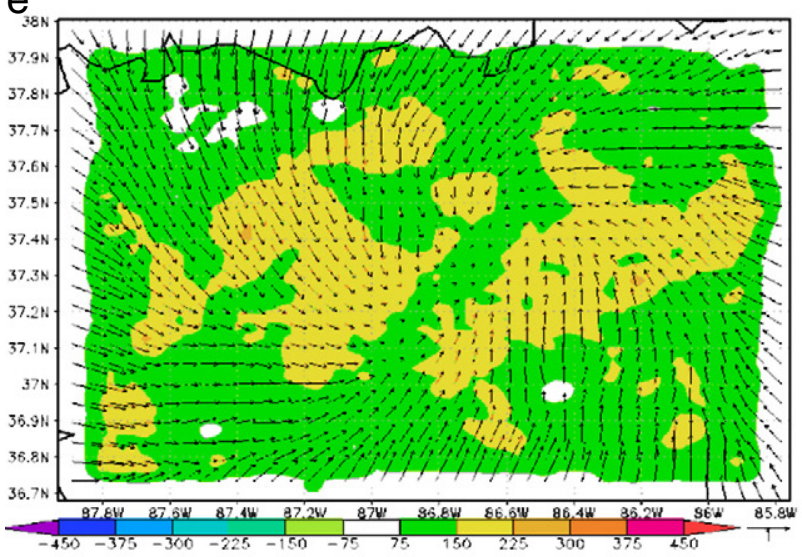

g

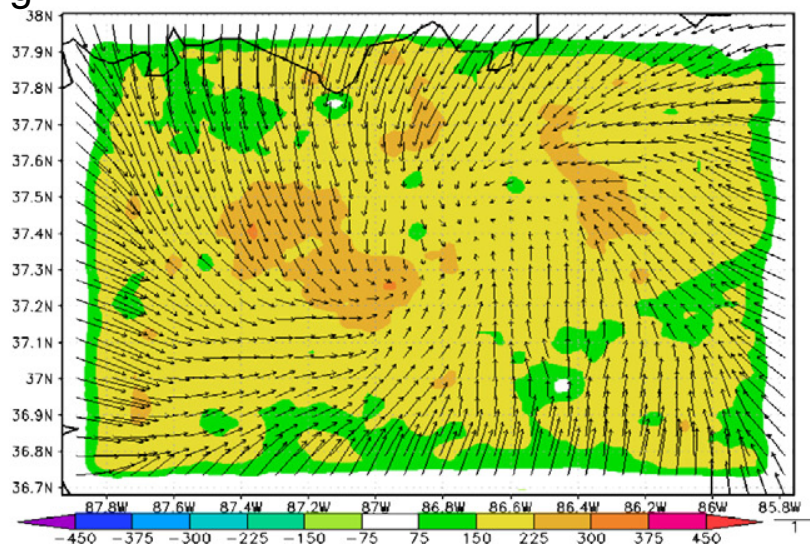

b
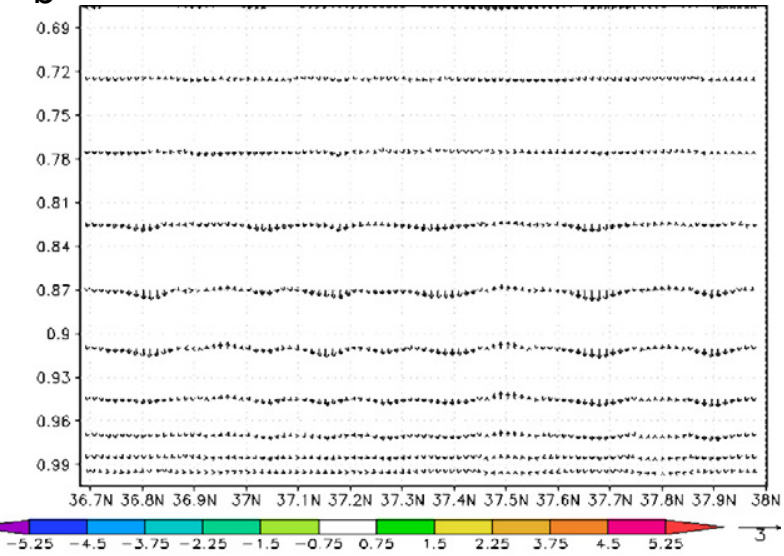

d
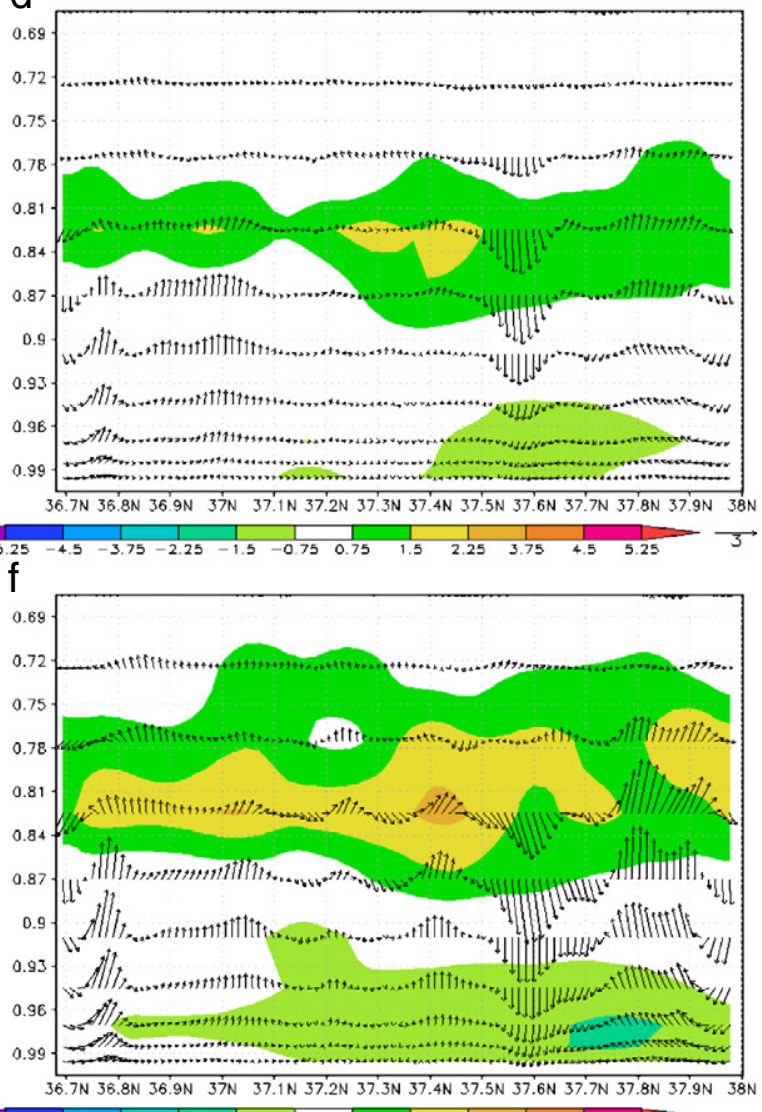

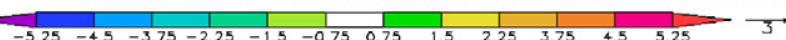
$\mathrm{h}$

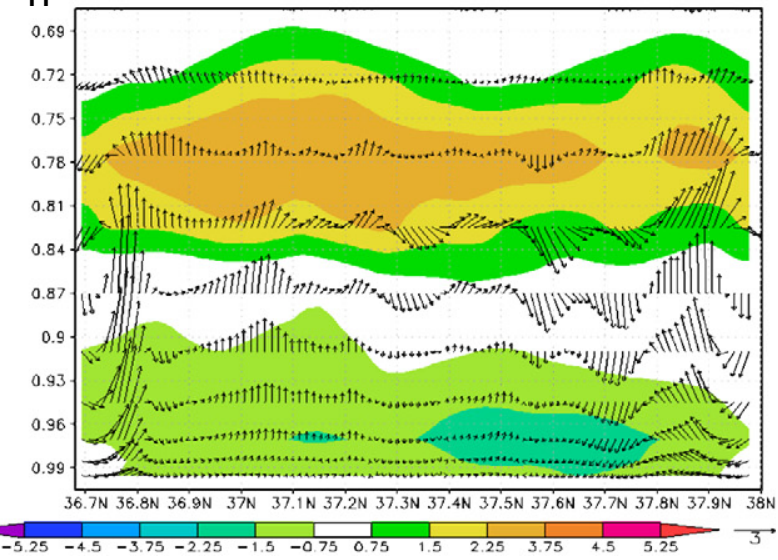




\subsubsection{Dry bare soil experiments}

Simulated surface fluxes over bare soil were further sensitive to decreases in initial soil moisture. Domain average latent (sensible) heat flux was reduced (increased) with decreasing soil moisture (Table 8). The reduction in available subsurface moisture has reduced simulated atmospheric moisture and increased temperature and PBL heights.

It is found that PBL height and horizontal wind field differences varied in response to decreases in initial soil moisture. Simulated PBL heights over bare soil were greater than CTRL with increasing differences within the inner domain as the soil became drier. As a result of elevated PBL heights, horizontal wind vector differences were oriented toward the domains center and increased in magnitude with reductions in soil moisture. Maximum horizontal wind speed differences were greater than CTRL by $1.2,1.8$, and $1.8 \mathrm{~ms}^{-1}$ for DRY05, DRY10, and DRY15 scenarios.

Lower $\theta_{e}$ differences were found from the surface up to $900 \mathrm{mb}$ and ranged between 3 and $6{ }^{\circ} \mathrm{C}$ less than CTRL. For the DRY10 and DRY15 bare soil runs, the strong vertical mixing within the PBL seems to have organized into a convective circulation similar to that found over both grassland and forest at 25\% FV. Overall, as expected, bare soil resulted in warmer and drier atmosphere and higher PBL heights compared with forest and grass.

\subsubsection{Wet bare soil experiments}

Increases in soil moisture over grassland and forest from 25 to $100 \% \mathrm{FV}$ and bare soil land uses had negligible effects on simulated near-surface atmosphere. This study found up to $269 \mathrm{~m}$ lowering of lifting condensation level (LCL) under WET15 and thus modified potential for cloud development. This is a notable finding under WET simulations. The model's insensitivity to increases in soil moisture for this study is due to an already moist root zone. FNL prescribed soil moisture across the domain is $0.36 \mathrm{~m}^{3} \mathrm{~m}^{-3}$. As suggested by McPherson (2007) and Oke (1987), increases in soil moisture elevate transpiration and evaporation rates up to a point where further increases have little or no effect, as was found in our experiments. It is also apparent that observational knowledge of the initial soil profile including temperature and moisture is critical in any soil moistureatmosphere feedback assessment as described by Dirmeyer et al. (2000).

\section{Final remarks}

This study investigated the impacts of historical land use changes on planetary boundary layer atmosphere in western Kentucky under summer time dry and weak synoptic conditions. Moreover, recent and potential future changes were also considered. Grass represented seasonal LULCC introduced by the Native Americans and early European settlers. Forest represented predominant historical and recent LULC and bare soils extreme future changes. To fulfill the objective of the study a number of sensitivity experiments were conducted. The results presented here emphasize the importance of LULC, FV, soil moisture, and atmospheric interactions. Many of the previous modeling studies have focused on LULCC and its impacts on atmosphere. However, there is a lack of studies highlighting the combined impacts of LULCC, FV, and soil moisture. To the best of authors' knowledge, this is the first study that has coupled systematic changes in soil moisture with LULC and FV.

Changes in LULC and FV under summer time dry and weak synoptic atmospheric conditions impacted the energy balance, atmospheric moisture content, near surface temperatures, and PBL characteristics, including wind fields. Compared to forest ( 1700-1900s), grass $(\sim 1700$ s) LULC resulted in increased latent energy flux and lower the $2 \mathrm{~m}$ temperature and lower PBL heights. Bare soils ( 2000s) resulted in lower (higher) latent (sensible) heat flux compared to grass and forest. It is also found that bare soils produced the highest overall PBL heights.

In addition, altered PBL wind fields supported both moisture convergence and divergence over the inner domain, modified PBL stability, and initiated meso-scale circulations. It is also found that the combined impact of modeled changes in LULC and FV may either enhance or reduce overall simulated differences compared to CTRL. For example, grass land use resulted in higher latent energy flux compared to CTRL. However, it was much lower under 25\% FV and further enhanced under $100 \% \mathrm{FV}$. Moreover, the impacts of FV on simulated results are sensitive at the diurnal scale. During the evening hours differences diminishes.

Atmospheric sensitivity to reductions in soil moisture was dependent upon LULC and FV. In general, it was found that modifications of LULC and FV that yield higher evapotranspiration rates, offset the simulated impact of drier soils as found by Chen and Avissar (1994). For example, grassland was slightly less sensitive to reductions in soil moisture than forest due to a lower stomatal resistance. Also, increases in FV for both grassland and forest mitigated the atmospheric response reduced soil moisture.

More importantly, changes in soil moisture modified PBL structure and 3-D wind fields. It was found that drier soil increased PBL height by limiting transpiration through vegetation stress (stomata closure), which increased sensible heat flux and vertical mixing within the PBL, as described by Oke (1987). Along the domain border, convectively driven vertical mixing was found to organize into meso-scale circulations like those described by Ookouchi et al. (1984) and Chen and Avissar (1994) due to distinct contrasts in soil moisture along the boundary. In addition, reduced soil moisture coupled with low FV induced preferential meso-scale circulations within the modeled domain that were not simulated over more dense vegetation. It is hypothesized that these preferential mesoscale circulations arise from at least three sources: subtle differences in soil moisture, elevation [suggested by Smith et al. (1994)], or vigorous mixing within the PBL. In addition, we noted that the PBL sensitivity to these circulations was reduced as FV was increased. In some instances, the modeled circulations altered PBL stability and promoted vertical mixing within the free atmosphere and cloud development. It was also found that height of the LCL was increased under dry soil and low FV while decreased under wet soil and high FV. Moreover, coupling of atmospheric moisture convergence, increased vertical motion, and weakening stability within the PBL creates atmospheric conditions conducive for cloud development, precipitation, and convectively driven thunderstorms.

Land surface forcing on precipitation has many pathways. Thus, a given set of land surface condition may help in development of precipitation if certain atmospheric state is achieved. In other words, the risk of developing an extreme convective event or heat wave is possible. Several of our own studies demonstrate that when we change soil moisture we also change amount, timing, and location of precipitation (Quintanar et al., 2008, 2009; Sen Roy et al., 2011; Leeper et al., accepted for publication). Moreover, we have clearly demonstrated that potential for cloud development and precipitation was modified due to changes in LULC. Our discussions on modifications in $\theta_{e}$, PBL height and moisture convergence due to changes in LULC are directly linked to potential convective development.

In summary, as LULC, FV, and soil moisture changes in the past modified planetary boundary layer characteristics, meso-scale circulations, potential for cloud development, near surface temperature, and moisture content as shown in this study. Future changes would also

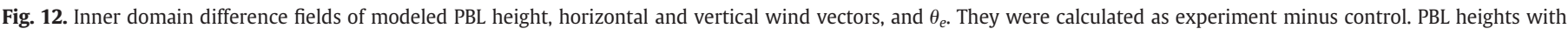

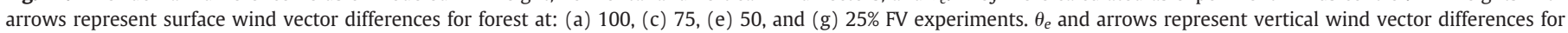
(b) 100 , (d) 75 , (f) 50 , and (h) $25 \%$ FV experiments. 
result in similar responses. In other words, local and regional weather and climate conditions would get modified. Obviously, near surface temperature and moisture changes may affect human comfort level. In addition, (an unintentional finding of) this study shows proper specification and initialization of soil moisture and FV must be addressed carefully during future modeling studies to improve accuracy because they could noticeably influence outcome. The findings also illustrate the need for a high quality, spatially dense meteorological network including of soil moisture monitoring instrumentations, such as the Kentucky Mesonet (www.kymesonet.org). The data from such a network will further help improvements in meso-scale model verification and simulation.

\section{Acknowledgments}

The authors would like to thank two anonymous reviewers, the editor, and Dr. Fei Chen for their comments and suggestions which have helped to improve this manuscript. This work has benefited from the USDA grant\# 58-6445-6-068. Technical assistance provided by Michael Grogan and Andrew Quilligan is much appreciated.

\section{References}

Adegoke, J.O., Pielke, R.A., Eastman, J., Mahmood, R., Hubbard, K.G., 2003. Impact of irrigation of midsummer surface fluxes and temperature under dry synoptic conditions: a regional atmospheric model study of the U.S. High Plains. Mon. Wear Rev. 131, 556-564

Adegoke, J.O., Pielke, R.A., Carleton, A.M., 2007. Observational and modeling studies of the impact of agriculture-related land use change on climate in the central U.S. Agric. For. Meteorol. 142, 203-215.

Barlage, M., Zeng, X., 2004. The effects of observed fractional vegetation cover on the land surface climatology of the community land model. J. Hydrometeorol. 5, 823-830.

Beltran-Przekurat, A., Pielke, R.A., Peters, D.P.C., Snyder, K.A., Rango, A., 2008. Modeling the effects of historical vegetation change on near-surface atmosphere in the northern Chihuahuan Desert. J. Ard. Env. 72, 1879-1910.

Betts, A.K., Ball, J.H., Beljaars, A.C.M., Miller, M.J., Viterbo, P.A., 1996. The land surfaceatmosphere interaction: a review based on observational and global modeling perspectives. J. Geophys. Res. 101, 7209-7225.

Brubaker, K.L., Entekhabi, D., Eagleson, P.S., 1993. Estimation of continental precipitation recycling. J. Clim. 6, 1077-1089.

Chang, J.T., Wetzel, P.J., 1991. Effects of spatial variations of soil moisture and vegetation on the evolution of a prestorm environment: a numerical case study. Mon. Wea. Rev. 119, 1368-1390.

Chen, F., Avissar, R., 1994. Impact of land-surface moisture variability on local shallow convective cumulus and precipitation in large-scale models. J. Appl. Meteorol. 33, 1382-1401.

Chen, F., Dudhia, J., 2001. Coupling an advanced land-surface-hydrology model with the Penn State-NCAR MM5 modeling system part I: model implementation and sensitivity. Mon. Wea. Rev. 129, 569-604.

Clark, C.A., Arritt, R.W., 1995. Numerical simulations of the effect of soil moisture and vegetation cover on the development of deep convection. J. Appl. Meteorol. 34, 2029-2045.

Colle, B.A., Olson, J.B., Tongue, J.S., 2003. Multiseasonal verification of MM5. Part I: comparison with the Eta Model over the Central and Eastern United States and impacts of MM5 resolution. Weather. Forecast. 18, 431-458.

Crawford, T.M., Stensrud, D.J., Mora, F., Merchant, J.W., Wetzel, P.J., 2001. Value of incorporating satellite-derived land cover data in MM5/PLACE for simulating surface temperatures. J. Hydrometeorol. 2, 453-468.

Cui, X., Graf, H.-F., Langmann, B., Chen, W., Huang, R., 2006. Climate impacts of anthropogenic land use changes on the Tibetan Plateau. Glob. Planet. Change 54, 33-56.

Dirmeyer, P.A., Zeng, F.J., Ducharne, A., Morrill, J.C., Koster, R.D., 2000. The sensitivity of surface fluxes to soil water content in three land surface schemes. J. Hydrometeorol. 1, 121-134.

Dobler, S., 2007. Personal Communication.

Douville, H., Chauvin, F., Broqua, H., 2001. Influence of soil moisture on the Asian and African monsoons. Part I: mean monsoon and daily precipitation. J. Clim. 14, 2381-2403.

Dudhia, J., 1993. A nonhydrostatic version of the Penn State-NCAR mesoscale model: validation tests and simulation of an Atlantic cyclone and cold front. Mon. Wea. Rev. 121, 1493-1513.

Ek, M.B., Holtslag, A.A.M., 2004. Influence of soil moisture on boundary layer cloud development. J. Hydrometeorol. 5, 86-99.

Findell, K.L., Eltahir, E.A.B., 2003. Atmospheric controls on soil moisture-boundary layer interactions: three-dimensional wind effects. J. Geophys. Res. Atmos. doi:10.1029/ 2001JD001515, 2003.

Fu, C., 2003. Potential impacts of human-induced land cover change on East Asia monsoon. Glob. Planet. Change 37, 219-229.
Gero, A.F., Pitman, A.J., 2006. The impact of land cover change on a simulated storm event in the Sydney basin. J. Appl. Meteorol. Clim. 45, 283-300.

Gordon, D.M., 1953. The Indian as an ecological factor in the northeastern forest. Ecol. $34,329-346$.

Grasso, L.D., 2000. A numerical simulation of dryline sensitivity to soil moisture. Mon. Wea. Rev. 128, 2816-2834.

Grossman-Clarke, S., Zehnder, J.A., Stefanov, W.L., Liu, Y., Zoldak, M.A., 2005. Urban modifications in a mesoscale meteorological model and the effects on near-surface variables in an arid metropolitan region. J. Appl. Meteorol. 44, 1281-1297.

Hammett, J.E., 1992. The shapes of adaptation: historical ecology of anthropogenic landscapes in the southeastern United States. Landscape Ecol. 7, 121-135.

Higgins, R.W., Mo, K.C., Schubert, S.D., 1996. The moisture budget of the central United States in springs as evaluated in the NCEP/NCAR and the NASA/DAO reanalyses. Mon. Wea. Rev. 127, 939-963.

Hoffmann, W.A., Jackson, R.B., 2000. Vegetation-climate feedbacks in the conversion of tropical savanna to grassland. J. Clim. 13, 1593-1602.

Jacquemin, B., Noilhan, J., 1990. Sensitivity study and validation of a land surface parameterization using the HAPEX-MOBILHY data set. Boundary Layer Meteorol. 52, 93-134.

Kentucky Climate Center, 2008. Index. Available via Mean Temperature. http://kyclim. wku.edu/webGallery/MeanTMaps/index.htm. Accessed 29 Feb 2008.

Kentucky Division of Conservation, 2008. Green River Crep. Accessed in December 2008 http://www.conservation.ky.gov/programs/crep/.

Leeper, R., Mahmood, R., Quintanar, A.I., 2009. Near surface atmospheric response to simulated changes in land-cover. Vegetation Fraction, and Soil Moisture over Western Kentucky. : Publications in Climatology, Vol. 62. 2, p. 41.

Leeper, R., Mahmood, R., Quintanar. A. I. (accepted for publication). Influence of karst landscape on planetary boundary layer atmosphere: A Weather Research and Forecasting (WRF) model-based investigation. J. Hydrometeorol.

Legates, D.R., McCabe, G.A., 1999. Evaluating the use of "goodness-of-fit" measures in hydrologic and hydroclimate model validation. Water Resour. Res. 35, 233-241.

LeMone, M.A., Chen, F., Alfieri, J.G., Tewari, M., Geerts, B., Miao, Q., Grossman, R.L., Coulter, R.L., 2007. Influence of land cover and soil moisture on horizontal distribution of sensible and latent heat fluxes in southeast Kansas during IHOP_2002 and CASES-97. J. Hydrometeorol. doi:10.1175/JHM554.1.

Lyons, T.J., 2002. Clouds prefer native vegetation. Meteorol. Atmos. Phys. 80, 131-140

Mahmood, R., 1996. Scale issues in soil moisture modeling: problems and prospects. Progr. Phys. Geogr. 20, 273-291.

Mahmood, R., Hubbard, K.G., 2002. Anthropogenic land-use change in the North American tall grass-short grass transition and modification of near-surface hydrologic cycle. Clim. Res. 21, 83-90.

Mahmood, R., Hubbard, K.G., 2004. An analysis of simulated long-term soil moisture data for three land uses under contrasting hydroclimatic condition in the Northern Great Plains. J. Hydrolometeorol. 5, 160-180.

Mahmood, R., Hubbard, K.G., 2007. Relationship between soil moisture of near surface and multiple depths of the root zone under heterogeneous land uses and varying hydroclimatic conditions. Hydrol. Processes 21, 3449-3462.

Mahmood, R., Foster, S.A., Keeling, T., Hubbard, K.G., Carlson, C., Leeper, R., 2006 Impacts of irrigation on 20th century temperature in the northern Great Plains. Glob. Planet. Change 54, 1-18.

Mahmood, R., Pielke Sr., R.A., Hubbard, K.G., Niyogi, D., Bonan, G., Lawrence, P., Baker, B., McNider, R., McAlpine, C., Etter, A., Gameda, S., Qian, B., Carleton, A., BeltranPrzekurat, A., Chase, T., Quintanar, A.I., Adegoke, J.O., Vezhapparambu, S., Conner, G., Asefi, S., Sertel, E., Legates, D.R., Wu, Y., Hale, R., Frauenfeld, O.N., Watts, A., Shepherd, M., Mitra, C., Anantharaj, V.G., Fall, S., Lund, R., Nordfelt, A., Blanken, P. Du, J., Chang, H.-I., Leeper**, R., Nair, U.S., Dobler, S., Deo, R., Syktus, J., 2010. Impacts of land use land cover change on climate and future research priorities. Bull. Am. Meteor. Soc. 91, 37-46.

McAlpine, C.A., Laurance, W.F., Ryan, J.G., Seabrook, L., Syktus, J.I., Etter, A.E., Fearnside, P.M., Dargusch, P., Pielke Sr., R.A., 2010. More than $\mathrm{CO}_{2}$ : a broader picture for managing climate change and variability to avoid ecosystem collapse. Curr. Opin. Environ. Sustainability 2, 1-13. doi:10.1016/j.cosust.2010.10.001.

McCumber, M.C., Pielke, R.A., 1981. Simulation of the effects of surface fluxes of heat and moisture in a mesoscale numerical model. J. Geophys. Res. Atmos. 86, 9929-9938.

McPherson, R.A., 2007. A review of vegetation-atmosphere interactions and their influences on mesoscale phenomena. Progr. Phys. Geogr. doi:10.1177/ 0309133307079055

McPherson, R.A., Stensurd, D.J., 2005. Influences of a winter wheat belt on the evolution of the boundary layer. Mon. Wea. Rev. 133, 2178-2199.

Michaux, A., 1805. Travels west of the Alleghanies. In: Thwaites, R.G. (Ed.), Early Western Travels. The Arthur H. Clark Company Cleveland, OH 1904, pp. 222-228.

Miguez-Macho, G., Li, H., Fan, Y., 2008. Simulated water table and soil moisture climatology over North America. Bull. Am. Meteor. Soc. 89, 663-672.

Mitchell, K., 2001. README_2.2. Available via The NCEP Land-Surface Model LSM National Center for Environmental Protection. http://www.emc.ncep.noaa.gov/ $\mathrm{mmb} / \mathrm{gcp} /$ noahlsm/README_2.2.htm. Accessed 24 Nov 2007.

Narisma, G.T., Pitman, A.J., 2003. The impact of 200 years of land cover change on the Australian near-surface climate. J. Hydrometeorol. 4, 424-436.

National Center for Atmospheric Research, 2006. MM5. Available via Chapter 8: MM5 National Center for Atmospheric Research. http://www.mmm.ucar.edu/mm5/ documents/tutorial-v3-notes-pdf/mm5.pdf. Accessed 17 Nov 2006.

Nigam, S., Ruiz-Barradas, A., 2006. Seasonal hydroclimate variability over North American in global and regional reanalyses and AMIP simulations: varied representation. J. Clim. 19, 815-837.

NRC, 2005. Radiative Forcing of Climate Change: Expanding the Concept and Addressing Uncertainties. National Academies Press, Washington, DC. 
Oke, T.R., 1987. Boundary Layer Climates Routledge. New York.

Ookouchi, Y., Segal, M., Kessler, R.C., Pielke, R.A., 1984. Evaluation of soil moisture effects on the generation and modification of mesoscale circulations. Mon. Wea. Rev. 112, 2281-2292.

Pan, Z., Takle, E., Segal, M., Turner, R., 1996. Influences of model parameterization schemes on the response of rainfall to soil moisture in the Central United States. Mon. Wea. Rev. 124, 1786-1802.

Pielke, R.A., 2001. Influence of the spatial distribution of vegetation and soils on the prediction of cumulus convection rainfall. Rev. Geophys. 39, 151-177.

Pielke, R.A., Walko, R.L., Steyaert, L.T., Vidale, P.L., Liston, G.E., Lyons, W.A., Chase, T.N. 1999. The influence of anthropogenic landscape changes on weather in south Florida. Mon. Wea. Rev. 127, 1663-1673.

Pielke, R.A., Adegoke, J., Beltran-Przekurat, A., Hiemstra, C.A., Lin, J., Nair, U.S., Niyogi, D., Nobis, T.E., 2007a. An overview of regional land use and land cover impacts on rainfall. Tellus 59B, 587-601.

Pielke, R.A., Adegoke, J., Chase, T.N., Marshall, C.H., Matsui, T., Niyogi, D., 2007b. A new paradigm for assessing the role of agriculture in the climate system and in climate change. Agric. For. Meteorol. 142, 234-254.

Quintanar, A., Mahmood, R., Loughrin, J., Lovanh, N.C., 2008. A coupled MM5-Noah land surface model-based assessment of sensitivity of planetary boundary layer variables to anomalous soil moisture conditions. Phys. Geogr. doi:10.2747/02723646.29.1.54.

Quintanar, A.I., Mahmood, R., Motley, M.V., Yan, J., Loughrin, J., Lovanh, N.C., 2009. Boundary layer trajectory dispersion sensitivity to soil moisture conditions as simulated by the MM5 and the Noah Land Surface model. Atmos. Environ. 43, 3774-3785.

Raddatz, R.L., 2007. Evidence for the influence of agriculture on weather and climate through the transformation and management of vegetation: illustrated by examples from the Canadian Prairies. Agric. For. Meteorol. 142, 186-202.

Sauer, C.O., 1927. Geography of the Pennyroyal. The State Journal Company, Frankfort, Kentucky.

Schneider, N., Eugster, W., 2005. Historical land use changes and mesoscale summer climate on the Swiss plateau. J. Geophys. Res. Atmos. 110, 1-18.
Segal, M., Arritt, R.W., 1992. Nonclassical mesoscale circulations caused by surface sensible heat-flux gradients. Bull. Am. Meteorol. Soc. 73, 1593-1604.

Segal, M., Avissar, R., McCumber, M.C., Pielke, R.A., 1988. Evaluation of vegetation effects on the generation and modification of mesoscale circulations. J. Atmos. Sci. 45, 2268-2292.

Sen Roy, S., Mahmood, R., Niyogi, D.D.S., Lei, M., Foster, S.A., Hubbard, K.G., Douglas, E., Pielke Sr., R.A., 2007. Impacts of the agricultural Green Revolution induced land use changes on air temperatures in India. J. Geophy. Res. 112, D21108. doi:10.1029/ 2007JD008834.

Sen Roy, S., Mahmood, R., Quintanar, A.I., Gonazalez, A., 2011. Impacts of irrigation on dry season precipitation in India. Theor. Appl. Clim. doi:10.1007/s00704-010-0338-z.

Shen, J., 1998. Numerical modeling of the effects of vegetation and environmental conditions on the lake breeze. Boundary-Layer Meteorol. 87, 481-498.

Smith, E.A., Wai, M.M.-K., Cooper, H.J., Rubes, M.T., 1994. Linking boundary-layer circulations and surface processes during FIFE 89. Part I: observational analysis. J. Atmos. Sci. 51, 1497-1529.

Sud, Y.C., Smith, W.E., 1985. Influence of local land-surface processes on the Indian monsoon: a numerical study. J. Clim. Appl. Meteorol. 24, 1015-1036.

Ter Maat, H.W., Hutjes, R.W.A., Ohba, R., Ueda, H., Bisselink, B., Bauer, T., 2006. Meteorological impact assessment of possible large scale irrigation in Southwest Saudi Arabia. Glob. Planet Change 54, 183-201.

Trenbreth, K.E., Guillemot, C.J., 1998. Evaluation of the atmospheric moisture and hydrologic cycle in the NCEP/NCAR reanalyses. Clim. Dyn. 14, 213-231.

Waisanen, P.J., Bliss, N.B., 2002. Changes in population and agricultural land in conterminous United States counties, 1790 to 1997. Global Biogeochem. Cycles 16, 1137-1156.

Zeng, X., Rao, P., Defires, R.S., Hanson, M.C., 2003. Interannual variability and decadal trend of global fractional vegetation cover from 1982 to 2000. J. Appl. Meteorol. 42, 1525-1530.

Zhang D. Anthes, R.A. 1982. A high-resolution model of the planetary boundary layersensitivity tests and comparisons with SESAME-79 data. J. Appl. Meteorol. 21, 1594-1609. 